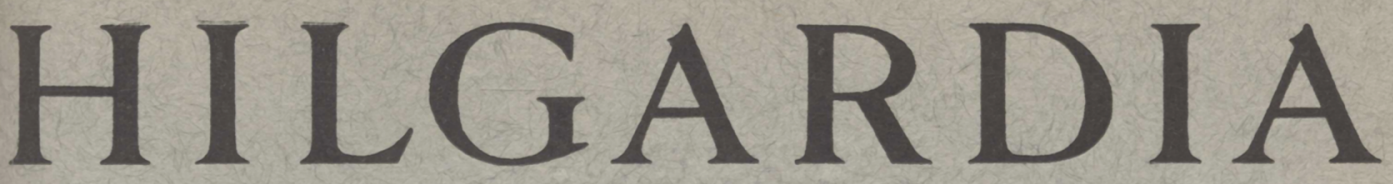

A Journal of Agricultural Science Published by the California Agricultural Experiment Station

\title{
GENETICS AND DEVELOPME
OF NINE MALE-STERILE TOMATO MUTANTS
}

CHARLES M. RICK 


\section{CONTENTS}

Summary $\quad$ Page

Introduction . . . . . . . . . . . . . 600

New male-sterile mutants . . . . . . . . . . 601

Tests of allelism . . . . . . . . . . . . 601

Inheritance . . . . . . . . . . . . 605

Macroscopic characteristics . . . . . . . . . . 606

Development of anthers . . . . . . . . . 609

Microsporogenesis and development of the male gametophyte in the normal type . . . . . . . . . . 611

Development of the tapetum and other tissues in the normal type. . . . . . . . . . . . . 611

Development of anthers in the mutant types . . . . 612

General aspects of anther development . . . . . . . 619

Ovule fertility . . . . . . . . . . . . . 621

Rates of natural cross-pollination . . . . . . . . . . 623

Frequency of male-sterile mutations . . . . . . . . . 629

Absence of cytoplasmically male-sterile mutants . . . . 630

Absence of female-sterile mutants . . . . . . . . 630

Use of the male-sterile mutants for controlled cross-pollination 631

Acknowledgments . . . . . . . . . . . . . 632

Literature cited . . . . . . . . . 633 


\section{H I L G A R D I A}

A Journal of Agricultural Science Published by

the California Agricultural Experiment Station

VoL. 18

DECEMBER, 1948

No. 17

\section{GENETICS AND DEVELOPMENT OF NINE MALE-STERILE TOMATO MUTANTS ${ }^{1}$}

\section{CHARLES M. RICK}

\section{SUMMARY}

A search was conducted in commercial plantings of the San Marzano tomato for male-sterile mutants, potentially useful in producing $F_{1}$ hybrid seed and in cross-breeding. Among 150 unfruitful plants, 12 were found to be genetically male-sterile. Breeding results indicate that the male sterility of each mutant is determined by a single recessive gene. One gene- $m s_{5}$ - was recovered four times. Eight other nonallelic genes- $m s_{6}$ to $m s_{13}$-were demonstrated. No mutants for female sterility or cytoplasmic male sterility were found.

In the mutant $m s_{5}, 3$ to 5 per cent of the microsporangia produced functional pollen; by using this pollen in self-pollination, pure-breeding male-sterile populations of $m s_{5}$ were obtained. No functional pollen was produced by other mutants.

The growth of anthers and, to a lesser extent, petals is suppressed to different degrees in the different mutants. The male-sterile segregates in some mutants can be identified macroscopically by the size and form of the floral parts, and in all of the mutants by the anther contents. Anthers are reduced most and breakdown of microsporogenesis occurs earliest in the four mutants whose petal length is significantly diminished. No effects of the genes were observed in other parts of the plant.

The genes for male sterility exert their most profound effects on the pollen mother-cells and early microsporogenesis. The mutants differ in time and rate of breakdown. The behavior of chromosomes is normal until the time of breakdown and does not seem to account for failure of pollen development.

Each gene affects tapetal development differently; in most mutants the breakdown is delayed, but in a few it occurs at the normal time or earlier. Pollen production is disrupted earliest in those mutants in which tapetal degeneration is delayed. Breakdown of microsporogenesis in $m s_{5}$ involves an erratic orientation of sporogenous tissue, the latter usurping the locus of the outer tapetum and wall tissue.

${ }^{1}$ Received for publication April 1, 1948.

${ }^{2}$ Assistant Professor of Truck Crops and Assistant Geneticist in the Experiment Station. 
These effects are determined precisely and consistently, each preparation of a given mutant revealing the same pattern of breakdown.

Counts of seed set after cross-pollination and examination of sectioned ovaries revealed no appreciable ovule sterility in any mutant except $m s_{8}$. In the latter about 25 per cent of the ovules abort-not so many as to disqualify it as a pistillate parent for hybrid-seed production.

The rates of natural cross-pollination of certain of the mutants differ with high statistical significance. The highest rate was observed in $m s_{5}$, which is subject to a low rate of natural self-pollination. In the other eight mutants the rate of natural cross-pollination shows some positive correlation with size of anther tube, suggesting that the insect pollen vectors prefer to visit flowers whose form deviates least from normal. The best mutants for hybrid-seed production are those intermediate in anther abnormality-enough for easy macroscopic identification but not enough to reduce cross-pollination greatly.

\section{INTRODUCTION}

Male-sterile mutants of the tomato, Lycopersicon esculentum Mill., are potentially useful in the production of $\mathrm{F}_{1}$ hybrid seed and in research requiring large-scale cross-pollination. Such mutants can be obtained in numbers from large field plantings so readily that it was feasible to secure nine of them, all within one variety, as subjects of the present study. They were analyzed genetically and compared in respect to the development of their anthers and other characteristics with the aim of finding the range of variation and of assessing each mutant in respect to its usefulness as a parent for hybrid-seed production.

The first example of male sterility known in tomatoes was a plant with "contabescent" anthers discovered by Crane (1915). The description of the appearance and fertility relations leave little doubt that this plant was malesterile, although Crane's paper did not treat the genetics of this condition. According to the much later publication of Lewis (1942), this male sterility was determined by a single recessive gene.

The next report of male sterility in tomatoes is that of Lesley and Lesley (1939). Their mutant differed from the fertile type only in having a different staining reaction and inviability of its pollen. Though it was proved that this condition is genetic, the data do not point to a definite mode of inheritance. The segregations suggest that two, or possibly three genes are concerned.

Another recessive gene that conditions male sterility was discovered later (Rick, 1944). In subsequent work (Rick, 1945a) with three American varieties of tomatoes, such male-sterile mutants comprised about 5 per cent of all extremely unfruitful plants, or about 0.005 per cent of all plants. Three additional male-sterile mutants were described, one belonging to each of the three tomato varieties investigated. Genetic male sterility, consequently, can be obtained in any desired variety, provided a sufficiently large planting is examined.

A search for additional male-sterile mutants was undertaken in 1944 . The study was planned to reveal the following information about the new mutants : (1) whether male sterility of each is determined by the same gene or by different genes ; (2) their mode of inheritance ; (3) their morphology and devel- 
opment; (4) the levels of their ovule fertilities; (5) their rates of natural cross-pollination; and (6) an evaluation of their usefulness in controlled cross-pollination.

In order to compare gene mutations in such respects, other genotypical variation should, of course, be held to a minimum. Hence the study was limited to a single horticultural variety-San Marzano. This does not imply that the mutants were isogenic, for genetic variation is known to exist within varieties; nevertheless, the study was not encumbered by the wide genetic differences that separate horticultural varieties.

Considerations of convenience largely governed the choice of the San Marzano variety. In order that plants be propagated by cuttings, a variety of indeterminate growth habit was needed. Its flower form should not be complicated by fasciation because in fasciated homozygotes, $f f$, the number and form of flower parts is quite variable (Zielinski, 1945). Heavily fruiting plants growing in large, accessible plantings were needed so that numerous male-sterile mutants might be obtained. The only variety that satisfied these requirements was San Marzano, the Italian pear tomato, grown to a large extent in central California for the processing of paste, catsup, and whole fruits.

\section{NEW MALE-STERILE MUTANTS}

About 150 unfruitful plants of the San Marzano variety were examined in this survey. The diploids were distinguished from heteroploids, and the malesterile mutants were tentatively identified in the field according to methods already described (Rick, 1945b). Of 42 diploids thus distinguished and later confirmed by actual chromosome counts, 12 yielded $\mathrm{F}_{2}$ generations that segregated for male sterility. The 8 per cent of male-sterile mutants obtained in this sample of unfruitful plants corresponds with the 5 per cent discovered in the earlier survey (Rick, 1945a). The percentages of other types of gene mutations and of heteroploids that greatly reduce fruitfulness were also similar to those found in the earlier study. Except for tests of allelism with three previously found mutants, the present report is limited to the 12 mutants in whose later generations male sterility was recovered.

According to preliminary observations, each of these 12 unfruitful plants corresponded to the definition of male sterility : each failed to produce functional pollen, yet each would produce fruits and seeds normally after transfer of pollen from fruitful diploids. The fertile $\mathrm{F}_{1}$ plants obtained proved that each of the 12 mutations is recessive, and segregations in the first small $\mathrm{F}_{2}$ populations suggested that male sterility in each is determined by a single gene.

\section{TESTS OF ALLELISM}

The next step in this study was to establish the genetic identity of the 12 mutants - that is, to discover which, if any, of them are allelic. For this purpose, crosses were made between all mutants in all possible combinations. The previously described mutants $m s_{1}$ (hybrid breeding stock), $m s_{2}$ (Pearson), and $m s_{3}$ (San Marzano) were included in these test crosses because their identity had not been tested previously; although it had been assumed that they were different genes because they differed in their morphological effects (Rick, 1945a). 


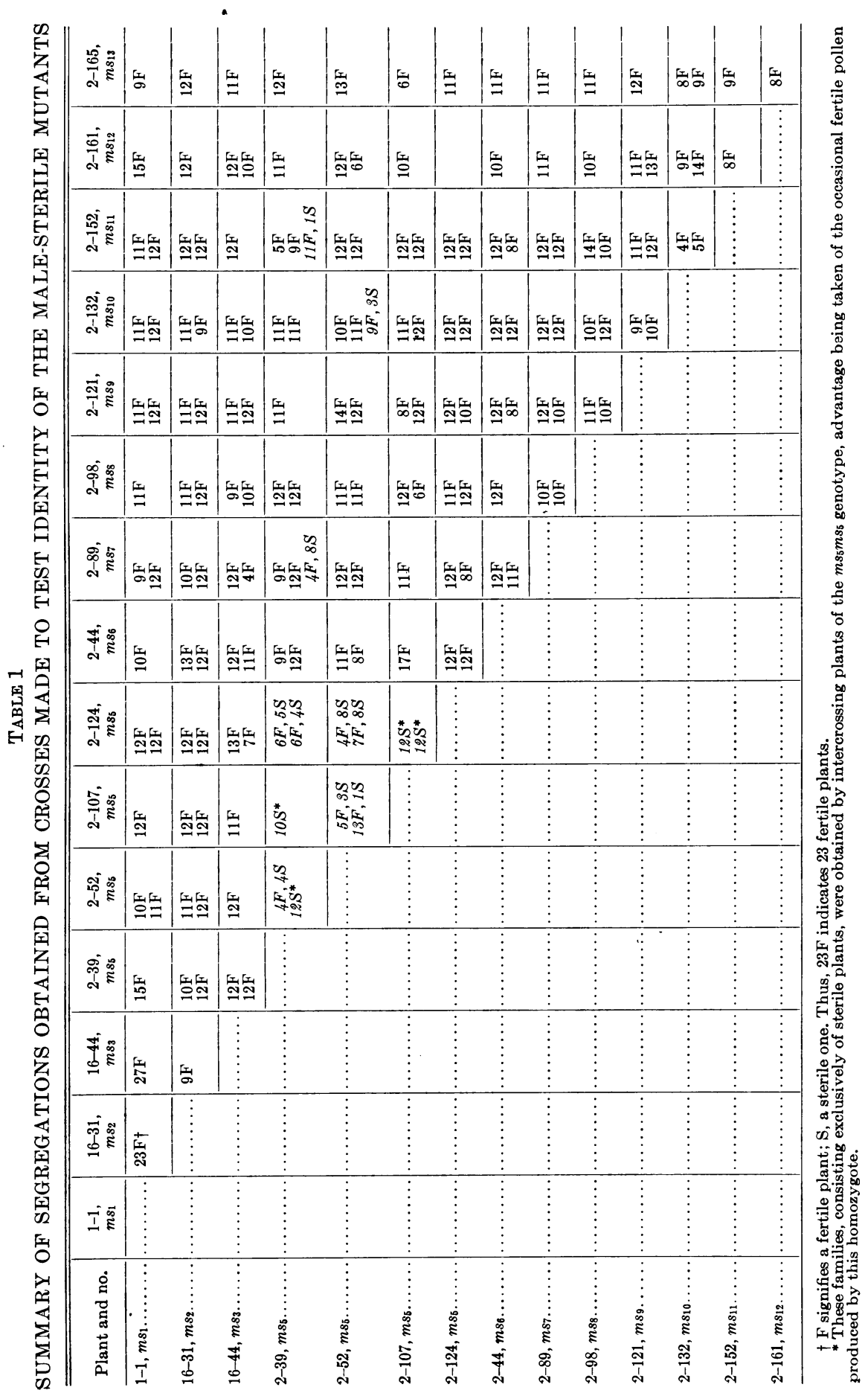


Each cross consisted of a transfer of pollen from the heterozygote of one mutant to the homozygous recessive form of another, the operation being facilitated by the male-sterile condition of the latter, which obviated emasculation. If the genes in both parents were allelic, this would amount to a backcross, and a segregation of approximately 50 per cent fertile and 50 per cent male-sterile plants would be expected. If the genes were not allelic, only fertile plants would appear. According to the binomial distribution in backcross expectation, there is only one chance in $2^{8}=256$ that all individuals in a population of 8 would be fertile if the genes were allelic. Every effort was therefore made to secure test families of 8 or more plants in the 105 possible combinations of the 15 mutants.

The plants of these test families were grown and the phenotypes determined according to the methods outlined in the following section.

The segregations observed are presented in table 1. Duplicate and triplicate entries in any space usually indicate that direct and reciprocal crosses were tested, although in a few cases several crosses of the same direction were tested. Since male-sterile offspring appeared in all families of each of the six possible combinations of $2-39,2-52,2-107$, and $2-124$, these four mutants must be allelic. The genes in each are probably identical because no differences were observed in their effects. The symbol $m s_{5}$ is therefore applied to each of these mutants.

While these test crosses were being studied, it was discovered that malesterile segregates of $m s_{5}$ occasionally produce a small quantity of functional pollen ; consequently (as elaborated in the section on natural cross-pollination) they are subject to a low level of self-pollination. This condition was utilized to advantage by applying pollen of homozygous recessives instead of heterozygotes in subsequent test crosses. In such crosses allelism would be indicated by 100 per cent male-sterile progenies; while nonallelic combinations would be indicated by 100 per cent fertile progenies, and an $F_{1}$ consisting of a single plant would therefore provide an adequate test. Several families of 100 per cent male-sterile plants were actually obtained in this fashion (table 1). Production of viable pollen has not been observed at any time in any of the other male-sterile mutants.

In the light of these facts, several apparent discrepancies in table 1 can be explained. Three families in other test crosses $(2-39 \times 2-89,2-39 \times 2-152$, and 2-52 $\times 2-132$ ) also segregated for male sterility. Since the male sterility of $2-39,2-52,2-107$, and $2-124$ is determined by the same gene, all crosses between these four mutants and any other single mutant constitute duplicate tests of a single combination. Thus the three segregating families prove to be exceptional because each one disagrees with seven or eight other families consisting exclusively of fertile plants that test the same combination. In other words, if these segregations indicate that 2-89, 2-152, and 2-132 are allelic with $m s_{5}, 23$ other families should also segregate, but none of them does. Since each exceptional family is generated by a cross between $m s_{5}$ as the pistillate parent and some other mutant as the staminate parent, the malesterile plants in these three exceptional families are construed as the products of self-pollination of the $m s_{5}$ parent. According to this explanation, the proportion of male-sterile plants in the exceptional families might be expected 


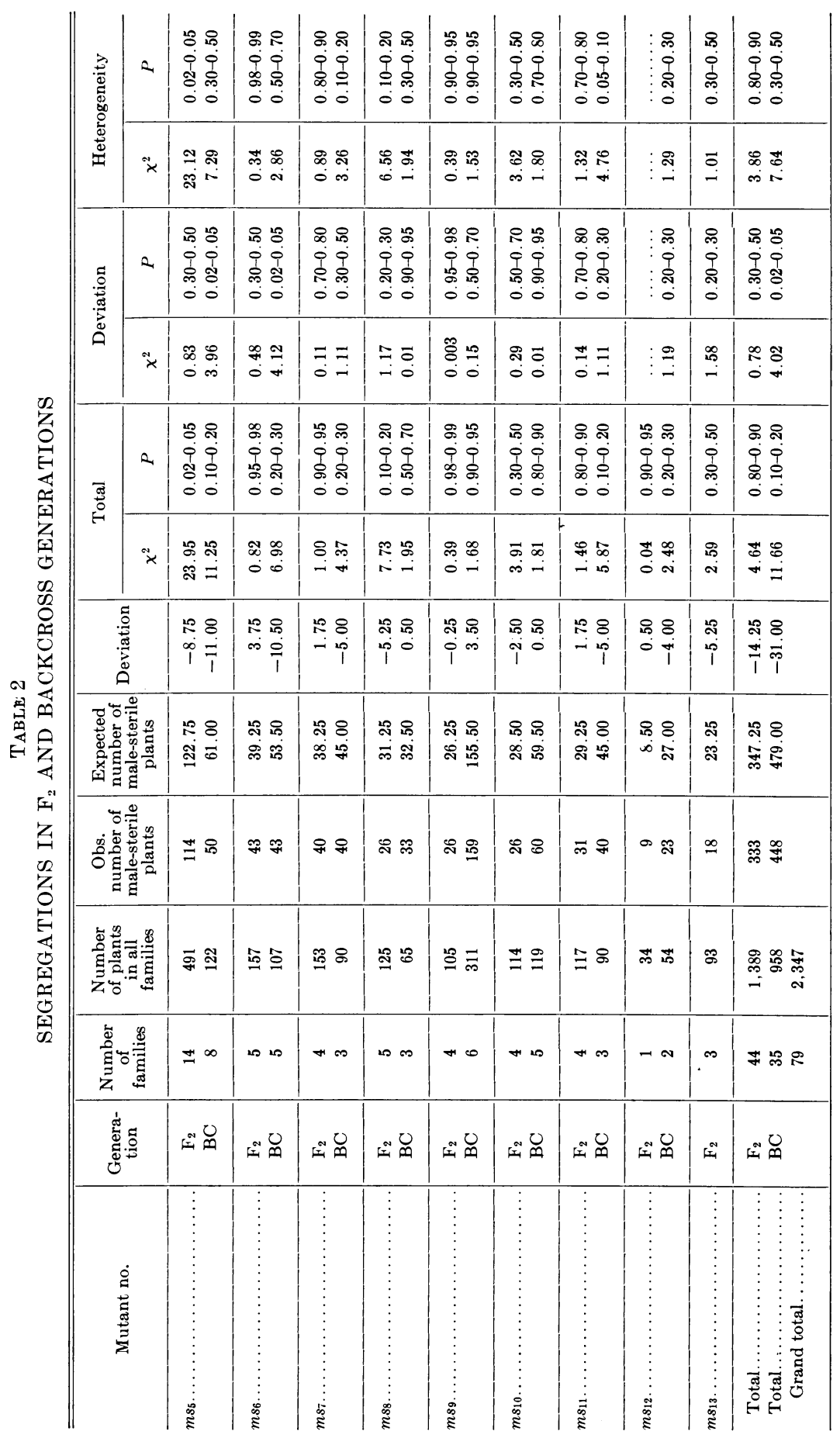


to be erratic and not to conform necessarily with a $1: 1$ ratio. This expectation is realized, for the proportions in the three families are 67,25 , and 8 per cent, the latter being a highly significant deviation from the 1:1 ratio.

The information that is apparently lacking in the absence of any family of the combination 2-124 $\times 2-161$ and is apparently deficient in the family of only 6 individuals in the combination $2-107 \times 2-165$ is supplied by the test crosses between the second parent of these crosses and the other representatives of $m s_{\tilde{5}}$.

Since the male sterility of each of the other mutants is determined by a different gene, the symbols $m s_{6}$ to $m s_{13}$ are applied to them in order of the sequence of their discovery. Of the 12 original male-sterile plants discovered in this survey, therefore, nine are determined by different genes, the other three proving to be duplicates of one of the nine genes.

\section{INHERITANCE}

Backeross and $\mathrm{F}_{2}$ populations of the nine mutants were grown in 1945, 1946, and 1947. The population referred to here as a family consists only of the plants grown from seeds that were formed in á single fruit. By separating families in this manner it was possible to limit errors in pollination to the seeds of single fruits, and in this way avoid contamination of an entire seed lot of any given cross or selfing. Single-fruit families of the variety San Marzano consist of 15 to 60 plants.

The families were sown in nursery pots, from which the seedlings were transplanted to $2 \times 2$ inch spacing in flats; from the flats the plants were shifted to the permanent planting in the field, where they were spaced 1 foot apart in rows spaced 6 feet apart. This field spacing was sufficient for the plant to grow vigorously for the first 2 months, so that flower types could be identified reliably in the first three or four inflorescences.

The phenotype of each plant in these families and also in the test progenies of the preceding section was determined by examination of anther contents smeared in acetocarmine. This microscopic test was not necessary for accurate detection of any of the male-sterile mutants ; nevertheless, it was used in order to have absolute determination of all plants and also to observe how much different plants of the same mutant might vary in the contents of their anthers. Many of the same families were examined later in the season to see which plants had set fruit. With very few exceptions, unfruitfulness was observed only in those plants that had been identified earlier as male-sterile by the nature of their anther contents.

The observed segregations were compared with the expected values by means of the chi-square test, and the share of the chi-square contributed by heterogeneity between families of the $\mathrm{F}_{2}$, and the backcross of each mutant was computed. These data are summarized in table 2. According to these calculations, heterogeneity at the 5 per cent level of significance is indicated for only one group of data-namely, $\mathrm{F}_{2}$ families of the $m s_{5}$ mutant. No significance can be legitimately attached to this departure because, by its very definition, such a deviation might be expected to occur on the average once in every 20 groups. This single deviation appearing in 17 groups would therefore not be exceptional. 
Recessive monogenic inheritance is indicated for every mutant tested; the observed segregations conform well with expected values. Deficiencies in the numbers of male-sterile plants that are significant at the 5 per cent level exist in 2 of the 17 groups of data. The significance of 2 such deviations might be questioned in the same light as the evidence for heterogeneity. More noteworthy are the facts that both these deviations are deficiencies of male-sterile plants and that the latter are also deficient in the totals of all $F_{2}$ and backcross individuals. The departure is not significant in the $\mathrm{F}_{2}$ totals, but does exceed the number corresponding to the 5 per cent level of significance for the backeross totals.

Only in the case of $m s_{5}$ do both $\mathrm{F}_{2}$ and backcross progenies deviate in the same direction. Although the deficiency of recessives is statistically significant only in the backcross, the consistent deviation is suggestive. Since the great variability in size and contents of anthers (elaborated in a subsequent section) might have led to misclassification of recessives as dominants, this mutant might merit additional intensive genetic study.

These results correspond with the deficiency of recessive homozygotes reported for a great many Mendelian characters. It can be concluded, therefore, that male sterility in each of these nine mutants is conditioned by a single recessive gene.

\section{MACROSCOPIC CHARACTERISTICS}

For the sake of convenience, the diploid plants that exhibit normal fertility, whether heterozygous for $m s$ genes or homozygous for their dominant alleles, are designated here the "normal type" to contrast them with the mutant types.

Differences between the male-sterile and normal-type segregates of each of the nine mutants have been observed only in the flowers. Macroscopic differences in vegetative characters, by means of which the two types could be identified before plants flower, were eagerly sought, especially because they might be useful in large-scale production of male-sterile plants; but none were found.

Macroscopic differences in flowers, however, are readily seen in most of the mutants. As expected, these differences chiefly concern the anthers. Representative samples of anther tubes of the normal type and male-sterile segregates of each mutant were photographed at low-power magnification and are reproduced in plate 1 . The range of effects on anther form are shown to vary from the extremely reduced anthers of $m s_{5}$ and $m s_{10}$ to the least modified ones of $m s_{7}, m s_{9}$, and $m s_{13}$. The modification of anther form wrought by each gene appears consistently in the great majority of the flowers, except those conditioned by the gene $m s_{5}$.

The product of length and diameter of anther tube provides a measure of anther size that is useful for comparing mutants. The means of such products are included in table 3. According to these figures, all mutant anthers are smaller than normal. Though this difference is statistically significant in all comparisons with the normal type, the distributions in the case of $m s_{7}$ and $m s_{9}$ overlap that of the normal; therefore, even size determinations based on measurements would not always provide a reliable separation of fertile and sterile segregates. 
Certain of the male-sterile mutants differed from the normal in anther color (table 3 ). The departure from the normal orange-yellow color is sufficient in some of the mutants $\left(m s_{5}, m s_{10}, m s_{11}, m s_{18}\right)$ to be as useful in distinguishing sterile segregates from fertile ones as the differences in size and form. The deviation is always toward a paler color, varying from a tone only slightly lighter than normal, as in $m s_{13}$, to a decidedly lighter tone-a pale lemon yellow-as in $\dot{m} s_{10}$. Aside from these differences, a very noticeable brownish discoloration, concentrated in the region of the dehiscence slit is frequently observed in anthers of $m s_{5}$. Slight as the difference is in $m s_{13}^{-}$, it is an aid in identifying sterile segregates.

TABLE 3

SUMMARY OF MACROSCOPIC CHARACTERS OF THE FLOWER

\begin{tabular}{|c|c|c|c|c|c|c|c|}
\hline \multirow{2}{*}{ Mutant number } & \multicolumn{3}{|c|}{ Petal length } & \multicolumn{2}{|c|}{$\begin{array}{l}\text { Significance of } \\
\text { difference in } \\
\text { petal lengths }\end{array}$} & \multirow{2}{*}{$\begin{array}{l}\text { Anther } \\
\text { tube } \\
\text { length } \times \\
\text { diameter }\end{array}$} & \multirow{2}{*}{ Anther color } \\
\hline & $\begin{array}{c}\text { Mean of } \\
\text { fertile } \\
\text { segregates }\end{array}$ & $\begin{array}{c}\text { Mean of } \\
\text { sterile } \\
\text { segregates }\end{array}$ & $\begin{array}{l}\text { Differ- } \\
\text { ence }\end{array}$ & $t$ & $P$ & & \\
\hline$m s_{\text {s. }}$ & $\begin{array}{c}m m \\
12.96\end{array}$ & $\begin{array}{c}m m \\
11.40\end{array}$ & $\begin{array}{c}m m \\
-1.56\end{array}$ & -4.69 & $<0.01$ & 2.33 & $\begin{array}{l}\text { Lemon-yellow; frequent } \\
\text { brownish discoloration }\end{array}$ \\
\hline$m s_{6}$. & 11.39 & 10.94 & -0.45 & -1.01 & $0.3-0.4$ & 3.19 & Lemon-yellow \\
\hline$m s i$ & 12.84 & 13.00 & 0.16 & 0.42 & $0.6-0.7$ & 4.36 & Orange-yellow \\
\hline$m_{s} \ldots \ldots \ldots \ldots$ & 12.30 & 10.52 & -1.78 & -4.98 & $<0.01$ & 2.79 & Golden-yellow \\
\hline$m s{ }_{9} \ldots \ldots \ldots \ldots$ & 12.29 & 11.47 & -0.82 & -1.34 & $0.3-0.4$ & 4.13 & Orange-yellow \\
\hline$m s_{10} \ldots \ldots \ldots \ldots$ & 13.07 & 11.24 & -1.83 & -2.95 & $<0.01$ & 2.56 & Greenish-yellow \\
\hline$m s_{11} \ldots \ldots \ldots \ldots$ & 12.29 & 12.31 & 0.02 & 0.05 & 0.9 & 2.93 & Lemon-yellow \\
\hline$m s_{12} \ldots \ldots \ldots \ldots$ & 12.35 & 10.50 & -1.85 & -4.07 & $<0.01$ & 3.14 & Orange-yellow \\
\hline$m s_{13} \ldots \ldots \ldots \ldots$ & 11.88 & 11.63 & -0.25 & -0.46 & $0.6-0.7$ & 3.83 & Golden-yellow \\
\hline Normal type.... & $\ldots$ & $\ldots$ & 0.00 & $\ldots \ldots$ & $\ldots \ldots$ & 4.87 & Orange-yellow \\
\hline
\end{tabular}

No matter how similar to the normal type the anthers of certain malesterile mutants may appear, it is always possible to differentiate them from normal segregates by a macroscopic examination of the contents of their anther locules. By prodding the anthers apart with a flattened instrument, one can readily determine in the field whether or not pollen is produced. If aborted pollen is produced, as in $m s_{13}$ and other mutants, it can be distinguished from functional pollen by its much smaller mass. Although this method is more tedious than a casual examination of anthers, it is a macroscopic method that is always reliable for detecting the male-sterile segregates of each of the nine mutants.

The anther tubes in plate $1, C$, represent the extremes of the normal range of variation for $m s_{5}$. Flowers exhibiting various degrees of modification of the anthers within this range appear on the same plant at the same period, this range being typical of the $m s_{\overline{5}}$ gene and apparently independent of plant or seasonal differences.

Examination of a large number of flowers of this mutant has shown that the small amount of functional pollen it produces is generated by the anthers that most closely approach the normal type. Male-sterile mutants that produce limited quantities of functional pollen are also known in Zea (Beadle, 1932). 
Reduction of corolla size is another feature associated with the effects on anthers in some of the male-sterile mutants. For comparison, the petal length was measured in a single flower from each of 15 to 25 plants of each of the two segregates fertile and male-sterile-of backcross populations of the nine mutants. Such measurements of the sterile and fertile segregates of the same population are required to reveal the differences in corolla size, which are much less extreme than those in anther size. Means were computed and differences compared by means of Fisher's (1946) $t$ test (table 3). Highly

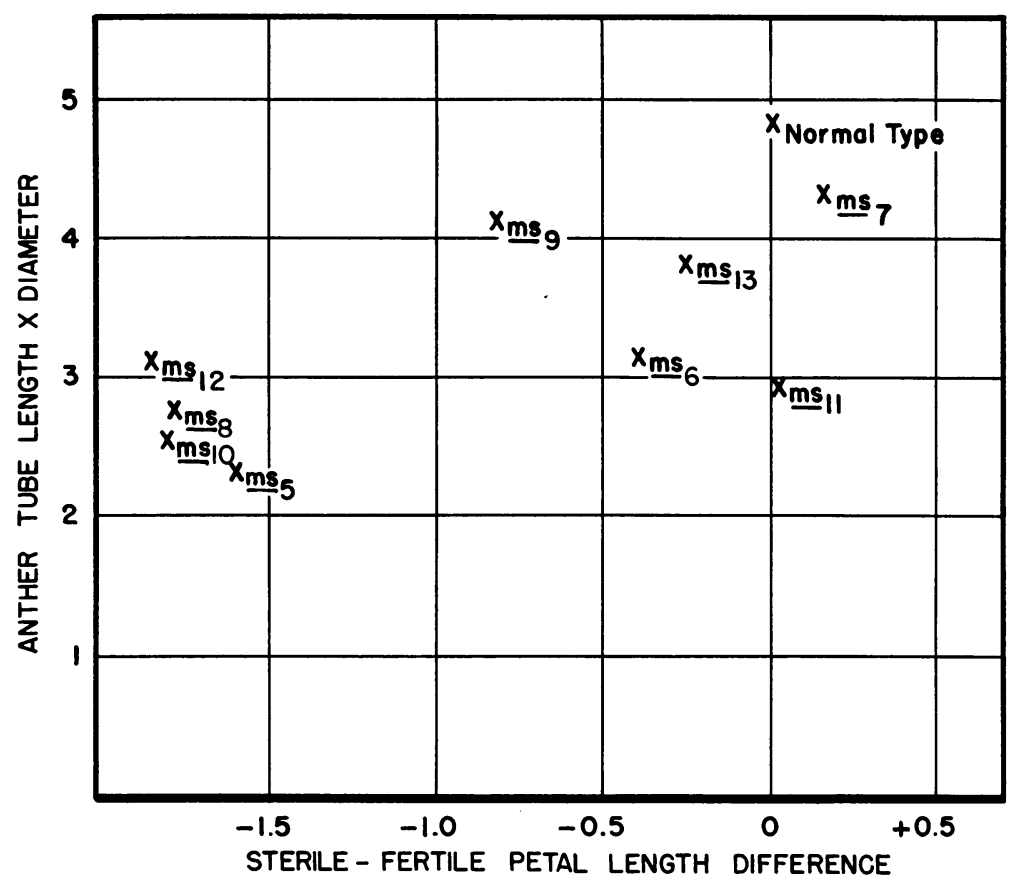

Fig. 1. Scatter diagram of the nine male-sterile mutants and the normal type, showing the relations between size of anther tube and length of petal.

significant decreases in petal length are characteristic of the male-sterile segregates of $m s_{\tilde{5}}, m s_{8}, m s_{10}$, and $m s_{12}$. In respect to the difference in petal lengths, these four mutants are sharply separated from the other five, in which any differences fall far short of significance. The gap between these two groups is illustrated in figure 1 , in which this difference between petal lengths is plotted against the anther-tube measurements for each of the nine mutants and the normal type. The anther-tube measurements for the four mutants having significantly shorter petals in the male-sterile segregates are also below those for the remaining group of mutants except $m s_{11}$ (table 3 and fig. 1 ). Within either group, however, the two variables do not seem to be correlated. This rather unusual segregation of the mutants also corresponds with the time of internal breakdown of the anthers and will be mentioned later.

Though four of the genes appreciably reduce petal lengths, the frequency distributions of fertile and sterile segregates overlap considerably in all cases. 
In other words, the effect on petal length is not nearly so drastic as the effects on anther length or girth, or the product of the two, for which measurements nonoverlapping distributions are obtained for all except two mutants.

\section{DEVELOPMENT OF ANTHERS}

The development of anthers of each of the mutants was studied and compared with similar stages of the normal type. The preparations consisted of fixed and sectioned anthers and others that were smeared directly in acetocarmine. Useful information was provided by both techniques; but the smears were more helpful as an aid to the study of pollen mother-cells and male gametophytes; while the sectioned preparations were necessary for a study of the nonsporogenous tissues and their temporal and spatial relations with the sporogenous tissue.

In a preliminary study of the preparations it soon became apparent that the action of the nine genes is essentially limited to the.pollen mother-cells, the subsequently developed male gametophytes, and adjacent tissues of the anther. As mentioned earlier, some of the genes tend to reduce the size of corollas and to have a still more drastic effect on size of anther, but these differences are not accompanied by striking internal changes except in the aforementioned tissues. Since such other tissues of the anther as the sterile parenchyma, conducting tissue, and the endothecium show no deviation, save possibly slight reductions in cell size, no reference will be made to their development except those aspects that might bear on the gene effects described.

This account is also limited in respect to time of development. In stages preceding the final mitoses that delimit the pollen mother-cells, no deviation from the normal type was observed in most of the mutants. Attention will therefore be directed mostly to the development from the time of differentiation of the pollen mother-cells until anthesis.

It was essential to establish the developmental age of the anthers before the mutants could be compared with the normal type. While size of anthers does provide a general approximation, it is not reliable for precise timing because anthers are considerably reduced in many of the mutants. The developmental stage of certain unaffected tissues of the flower provides a more exact measure of the relative age of the anthers. One example is the developmental sequence in petals : in transverse sections through the middle of the flower bud, petal primordia are well separated in early stages, approach each other later, and eventually meet and buckle inward in the dorsal groove of each anther. While the petals provide an adequate way to measure stages in early development, the length of epidermal hairs, which appear on the anthers in later stages (Rick, 1947), is more reliable for intermediate stages of this period. Timing of the final stages of development including anthesis of the flower can be followed accurately in the differentiation of those endothecial cells that regulate the opening of the dehiscence slit. In the final stages these cells elongate radially and they retain'an active condition longer than any other sterile cells of the anther. A complete delineation of all these sequences would not be warranted here. It is sufficient to say that by examining these tissues one can classify anthers without difficulty into numerous stages of development between the early differentiation of pollen mother-cells and anthesis. 


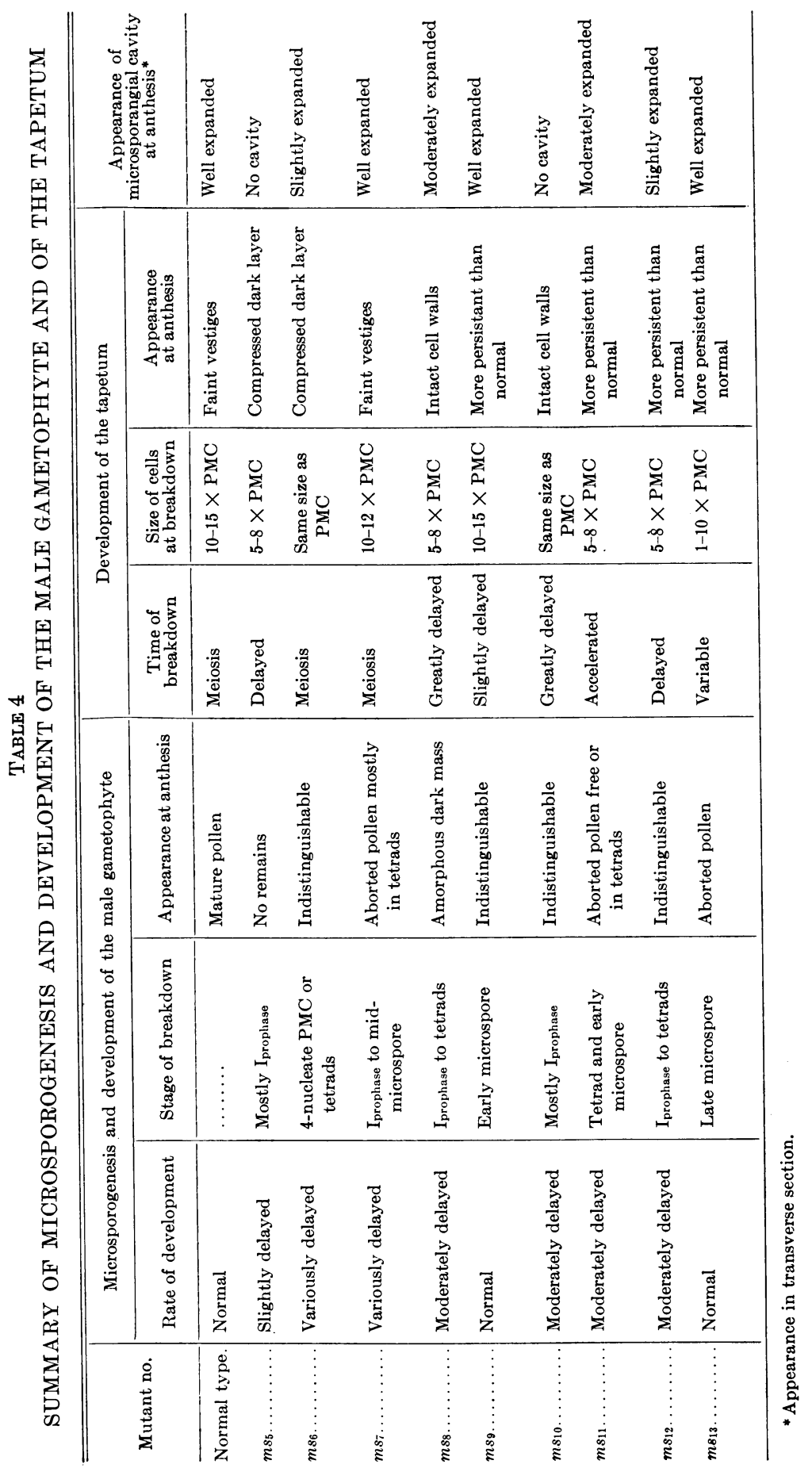


The substance of this section-that is, a comparison of the development of anthers of the nine mutants and the normal type-is presented in outline form in table 4.

The observations can be presented most efficiently by discussing first the development of the normal-type structures and by treating only those aspects of the mutants that depart from the normal pattern.

Microsporogenesis and Development of the Male Gametophyte in the Normal Type. Gametogenesis in the tomato, including the early development of floral organs and derivation of the sporogenous layers, has been described in detail by Smith (1935). Sporogenous tissue is differentiated very early in the development of the anther. As seen in a transverse section of the anther, it appears as a crescentic mass, several cells in thickness. The pollen mother-cells are readily distinguished from other cells by their very darkstaining cytoplasm. Their nuclei gradually enlarge until, in prophase of the first meiotic division, they nearly equal the volume of the cytoplasm of the cell. The two meiotic divisions proceed very rapidly, giving rise to a fournucleate pollen mother-cell. The four-nucleate stage and the subsequent one in which four microspores are delimited by cell walls persist for much longer periods than the meiotic divisions. After the uninucleate microspores are released from the old pollen-mother-cell wall, they quickly assume a spherical shape and enlarge until each finally reaches a volume comparable to that of the original pollen mother-cells.

The microspores become refractory for study of nuclear behavior early in this final period because their cytoplasm changes to a dense, granular condition. According to Smith a single mitosis occurs during this interval, the mature pollen grain containing a generative and a tube nucleus. The sequence of development giving rise to mature pollen grains in tomatoes, accordingly, is typical of many angiosperms.

Development of the Tapetum and Other Tissues in the Normal Type. In the tomato the tapetum is a single layer of cells that lines the microsporangial cavity and serves as a nutritive layer for the developing pollen mother-cells and subsequently developed microspores. In keeping with its nutritive function the tapetum develops cataclysmically.

The first evidence of the tapetum is seen in the single layer of cells on the adaxial side of the sporogenous layer. At the time the cells of the latter layer first appear darker, the former enlarge and become decidedly more vacuolate than the other adjacent cells. Somewhat later, sterile cells on the abaxial side differentiate in the same manner, until the sporogenous layer is completely enveloped by this layer of strikingly contrasting appearance. The nuclei of the tapetal cells enlarge rapidly and, in many instances, divide to produce permanently binucleate cells in early development. The cells enlarge so rapidly that, by the time the pollen mother-cells have reached mid-prophase of the first meiotic division, they have attained a volume ten to fifteen times that of the latter and have greatly distended the microsporangia. Fixation of the tapetum is most difficult at this time of maximum expansion.

Degeneration starts at various times, but is generally evident by the time of the first and second meiotic metaphases in the pollen mother-cells. The cells collapse to a dark-staining layer lining the greatly enlarged microsporangial 
cavity. Degeneration continues until, at anthesis, nothing of the tapetal cells remains but a threadlike vestige in the periphery of the cavity (plate $2, A$ ).

Since it is concerned in the development of one of the male-sterile mutants, the wall tissue of the anther should be mentioned here. At the time the sporogenous tissue is first differentiated, it is protected on the abaxial side by a layer three or more cells in thickness. Cell divisions continue until this layer is at least five cells thick. These cells are parenchymatous and are greatly flattened radially. As mentioned previously, the endothecium-the outermost layer of the anther wall nearest the junction of the two microsporangia of an anther lobe-develops in a special manner so as to serve as the disjunctive layer.

Development of Anthers in the Mutant Types. Discussion of development of $m s_{5}$ is withheld until the end of this section because its characteristics are exceptional.

$m s_{6}$. Microsporogenesis stops in the four-nucleate stage of the pollen mothercells or in the immediately subsequent tetrad stage. Development is normal up to meiotic prophase; after that meiosis is delayed to varying degrees. In some cases meiosis is still in progress in anthers in which large microspores would be present in the normal type. In spite of this variability, meiosis seems to proceed normally and to be completed in all pollen mother-cells. The tetrads or four-nucleate pollen mother-cells degenerate rapidly, and by anthesis nothing remains of them save an amorphous dark-staining layer (plate 2, $C$ ).

Tapetal cells of this mutant differentiate normally in early development, but never enlarge to any greater extent than the pollen mother-cells. In most preparations they begin to disintegrate at the same time as in the normal type despite their exceedingly subnormal size, although occasionally this disintegration is slightly delayed. Collapse and disintegration quickly follow, and the remains of this tissue may or may not line the periphery of the slightly enlarged microsporangial cavity. At anthesis the dark-staining mass of the tapetum is coalesced with the remains of the pollen mother-cells (plate 2, $C$ ).

$m s_{7}$. Gametogenesis is interrupted at various stages in this mutant. Abortion has been observed at all stages from prophase of meiosis to intermediate stages of microspore development. Cells that are affected in early stages are either resorbed or so greatly modified that they cannot be recognized as such at anthesis. Aborted microspores still adherent in tetrads are seen in fully half the anther smears of this mutant, and microspores aborted in later development also persist to anthesis in recognizable form. Though the stage of degeneration is variable in this mutant, the time of breakdown appears to be quite precise ; in other words, the rate of microsporogenesis varies considerably from one cell to another, but all cells of an anther degenerate at approximately the same time, some still being in various stages of meiosis, others having reached the microspore stage. Many of the aborted microspores are retained in tetrads, even until anthesis (plate $2, D$ ).

The tapetum develops normally in respect to the time of the different changes. The cells do not reach quite so large a size as they do in the normal type. The greatly enlarged locular cavities at anthesis attest to the expansion of the tapetal cells of this mutant. Only a faint vestige of them remains at anthesis (plate $2, D$ ). 
$m s_{8}$. Degeneration of microsporogenesis somewhat resembles that of $m s_{7}$. Breakdown may occur in various stages of meiosis from prophase to the formation of tetrads. It differs in timing, however, for all the meiotic figures appear somewhat later than they do in the normal type. The remains of pollen mother-cells appear at anthesis only as a compressed dark-staining mass (plate $2, E$ ).

The development of tapetal cells deviates from the normal type in the respect that it is delayed. Early differentiation of the cells appears normal, but they enlarge at a slower rate and finally reach a maximum size, only half that of tapetal cells in the normal type, much later than they do in normal material. The delay in development is also manifested in their slow disintegration, together with the fact that, at anthesis, most of the walls of the tapetal cells are still intact (plate $2, E$ ). In this last respect $m s_{8}$ differs strikingly from $m s_{6}$.

$m s_{9}$. Breakdown occurs with striking precision in the early microspore stage. All aspects of earlier development seem normal ; meiosis is not delayed, and it results in the formation of normal-appearing microspores, which are regularly released from their tetrad groupings. These microspores do not enlarge, however, but gradually lose their contents, until, at the time that they would normally be considered midway in their development into pollen grains, they have entirely lost their contents. At anthesis the microspores are so completely degenerated that they are scarcely recognizable (plate $2, F$ ). Even though microspores mostly degenerate later in $m s_{9}$ than in $m s_{7}$, they are more quickly resorbed.

Aside from a slight delay, the tapetum develops in $m s_{9}$ as it does in the normal type, the cells enlarging to nearly the same extent. The delay is manifested at anthesis by cell remains that are more persistent than in the normal type (plate $2, F$ ).

$m s_{10}$. Meiosis is initiated somewhat later than in the normal type. Degeneration occurs in early prophase of meiosis in all save about 15 per cent of the buds, in which a few cells are able to reach later stages, even as late as tetrads. Rapid degeneration follows, reducing the clumped pollen mother-cells to unrecognizable masses (plate $3, A$ ).

In some respects the sequence of tapetal development in $m s_{10}$ resembles that of $m s_{6}$. Early differentiation of the cells is normal, but enlargement is slow and greatly delayed. The tissue, in fact, never seems to degenerate, the cells appearing intact at anthesis, although generally lacking contents. Since the tapetum never shrinks, no cavity appears in the microsporangia at anthesis (plate $3, A$ ).

$m s_{11}$. The pattern of breakdown is similar in some respects to that of some of the mutants already discussed, but in every comparison it differs in certain characteristics. Early development, including meiotic prophase, is normal. Later stages of meiosis appear normal, but they are considerably delayed. Pollen mother-cells rarely disintegrate before the tetrad stage. About half the microspores abort while in tetrads; the remainder collapse after release. Whenever they break down, the microspores remain juvenile in size and form, slowly lose their cytoplasmic contents, and appear at anthesis as empty shells, either free or attached in tetrads (plate $3, B$ ). 
Tapetal development in $m s_{11}$ is anomalous inasmuch as disintegration begins slightly earlier than in the normal type, yet proceeds at a slower rate. In the earliest stages the cells increase in size at the normal rate, but they cease to do so long before they reach the great expansion attained in the normal type. Their subsequent contraction leaves moderately large cavities in the microsporangia. As in the case of $m s_{9}$, the cell walls are more or less intact at anthesis (plate $3, B$ ).

$m s_{12}$. The interruption of microsporogenesis is strikingly like that of $m s_{8}$. Meiosis is often considerably delayed, and cells may disintegrate at any stage from prophase until the formation of tetrads, although most collapse in prophase. The remains of the pollen mother-cells aggregate with the tapetum to form an irregular dark-staining layer at anthesis (plate $3, C$ ).

Tapetal cells develop somewhat more slowly than normal in $m s_{12}$. After reaching a volume of about half that of normal material they begin their degeneration at a later stage than normal. They deviate from the normal also in shifting toward the center of the cavity instead of toward the periphery. This behavior may account for the smallness of the locular cavity. The remains of the tapetum are more persistent in $m s_{12}$ than they are in the normal type (plate $3, C$ ).

$m s_{13}$. Male gametophytes reach a later stage of development in $m s_{13}$ than they do in any other mutant. All development is normal until microspores reach a fairly large size. Here their enlargement is arrested and they rapidly lose their cytoplasmic contents. They are easily recognized at anthesis as relatively large, but shriveled and empty microspores (plate $3, D$ ).

The tapetum develops in a more variable manner in $m s_{13}$ than in any other mutant. Some cells, for instance, may degenerate in very early stages before expanding to any extent; others may expand considerably, but never to the size realized in the normal type. The cells disintegrate, but not quite so completely as in the normal type (plate $3, D$ ).

$m s_{5}$. The description of development of $m s_{5}$ is delayed to this point because, in contrast to the other mutants, its microsporangia may follow different patterns of development. Only 3 to 5 per cent develop in the normal fashion and generate normal pollen. Most of the remainder deviate in a single general pattern, although a small percentage develop in an intermediate fashion.

From very early developmental stages of the anther, most microsporangia of this mutant are abnormal. As soon as the sporogenous cells assume their densely cytoplasmic character, it is observed that they consist not only of a C-shaped mass of two.cells' thickness, but also of all abaxial cells up to the epidermal layer (plate $3, F$ ). This anomalous condition persists through later stages and seems to be responsible for the final breakdown in pollen production. In 90 per cent of the microsporangia that deviate in this manner, pollen mother-cells degenerate in prophase of meiosis, the remainder collapsing somewhat later. Though the cells may collapse without any delay, meiosis is usually retarded.

In the deviating microsporangia, an abaxial tapetum apparently never appears where the sporogenous cells extend to the epidermis (plate $3, F$ ). The correspondence of tissues in early and late stages in the preparations gives this impression, yet it would be difficult to prove that outer cells of the 


\section{Plates}




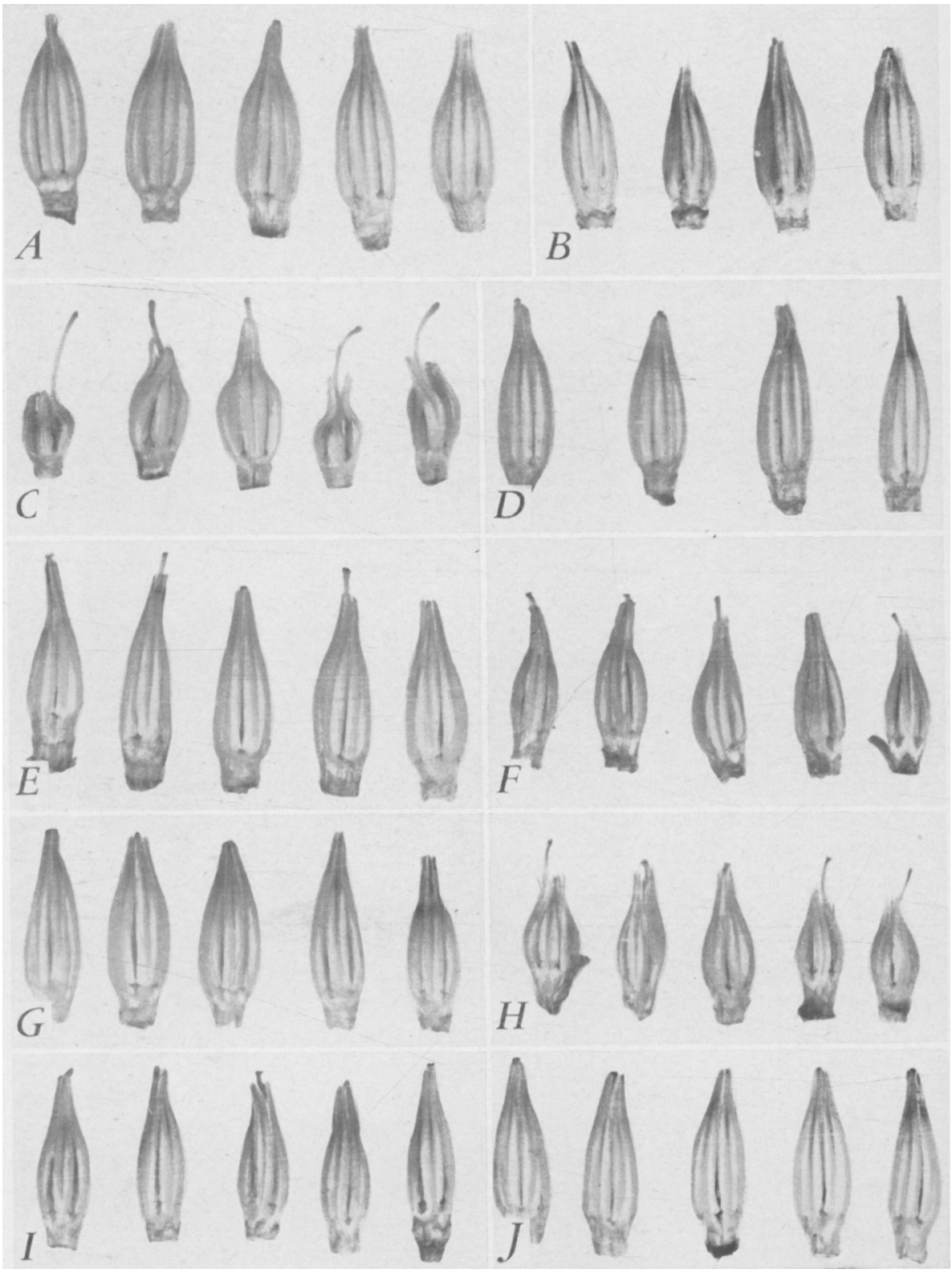

Plate 1. Anther tubes of the normal type and male-sterile mutants: $A$, normal type; $B, m s_{11} ; C, m s_{5}$; $D, m s_{1 i} ; E, m s_{-} ; F, m s_{\mathrm{s}} ; G, m s_{9} ; I I, m s_{10} ; I, m s_{12} ; J, m s_{13^{*}}($ All $\times 3$. 

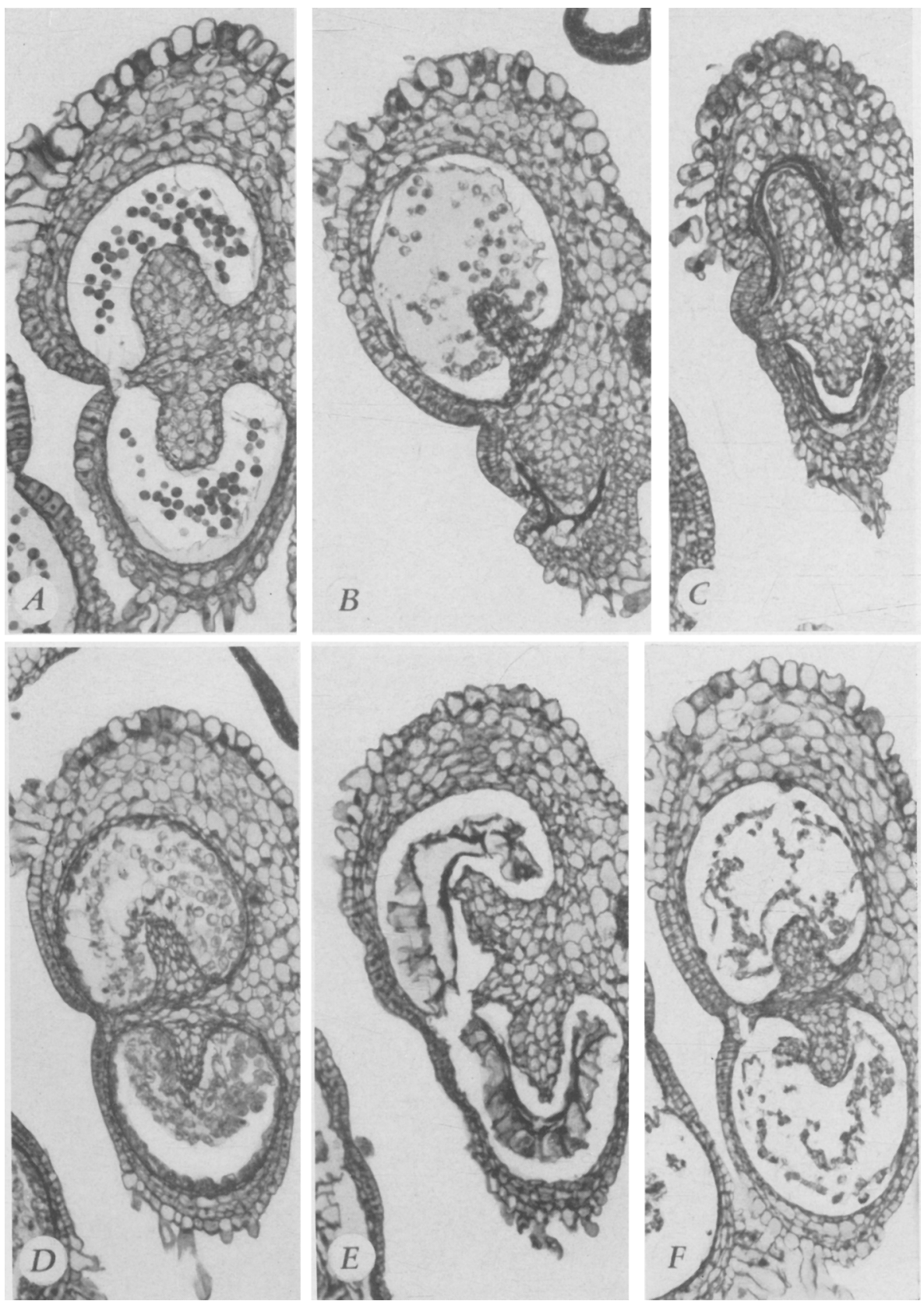

Plate 2. Transverse sections of anther lobes of the normal type and male-sterile mutants. All except $D$ were collected just prior to anthesis; $D$ represents a slightly earlier stage. $A$, normal type; $B, m s_{5}$, showing normal-type development in the upper microsporangium and the much more frequent degenera. tion in the lower microsporangium $; C, m s_{6} ; D, m s_{7} ; E, m s_{s} ; F, m s_{i j} .($ All $\times 100$. 

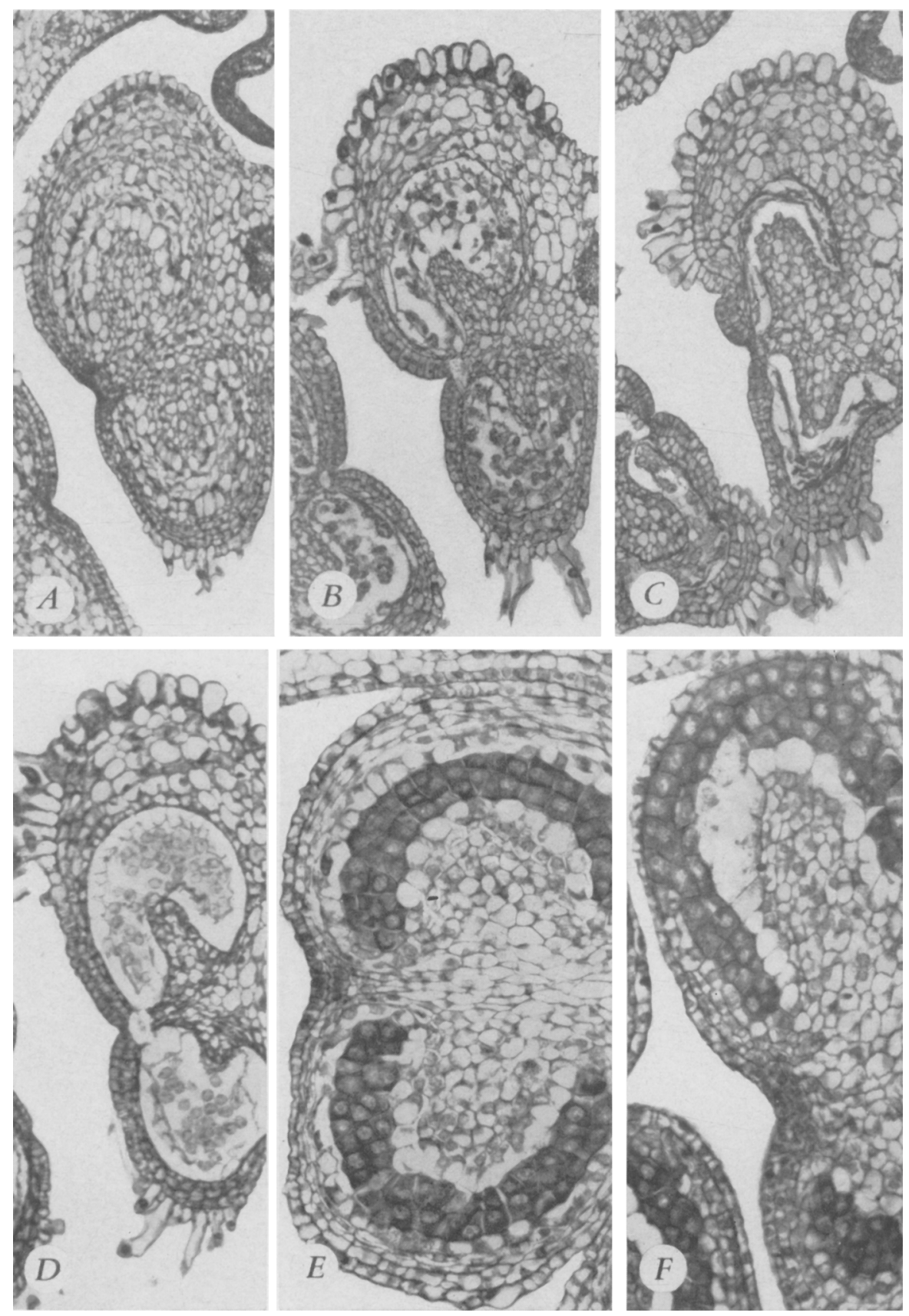

Plate 3. Transverse sections of anther lobes of male-sterile mutants. $A-D$ were collected just prior to anthesis; $E$ and $F$ represent an early stage in the differentiation of pollen mother-cells. $A, m s_{10}$; $B, m s_{11} ; C, m s_{12} ; D, m s_{13} ; E$, normal type, showing the location of the darkly stained pollen mother-cells; $F, m s_{5}$, showing aberrant location of pollen mother-cells in the upper microsporangium and normal location in the lower one. $(A-D, \times 100 ; E$ and $F, \times 200$.) 
dark-staining mass never develop tapetal properties. Tapetal cells develop continuously on the adaxial side and at either end of the mass of sporogenous cells on the abaxial side wherever sterile cells separate the sporogenous cells from the epidermis (plate $3, F$ ). Tapetal cells that differentiate develop at a slower rate, reach a lower maximum volume, and collapse later than in the normal type. At anthesis they appear as part of the dark, compressed layer that includes remains of the pollen mother-cells, or occasional cells may retain their normal outlines (plate $2, B$ ).

General Aspects of Anther Development. The considerations of anther development can be concluded with several statements of general significance:

1. The breakdown of microsporogenesis or of the male gametophyte occurs differently in each of the nine mutants. Cells may degenerate in different stages from early prophase of meiosis in the pollen mother-cells to relatively large microspores. Normal development of the early stages may proceed at the normal rate, or it may be delayed to varying degrees; furthermore, breakdown may differ in rate, even though it might start at the same time. The mutants $m s_{8}$ and $m s_{12}$ resemble each other to the greatest extent in this respect, but even in this pair, in which the breakdown occurs in all stages of meiosis, the pollen mother-cells tend to degenerate earlier and with less variation in $m s_{8}$ than in $m s_{12}$; furthermore, the pattern of tapetal development differs considerably in these two mutants.

2. Until the time of breakdown, meiotic chromosomes behave normally. In none of the mutants was there any evidence that abnormal chromosome behavior primarily causes the breakdown and consequent male sterility.

3. Development of the tapetum is affected in all mutants. The closest approach to normal development was observed in $m s_{7}$, but, even in this mutant, tapetal cells do not seem to reach normal maximum size. The patterns of deviation in this development are almost as varied as those of microsporogenesis : the tapetum may degenerate sooner than it does in the normal type $\left(m s_{11}, m s_{13}\right)$, at the same time $\left(m s_{7}\right)$, or later to varying degrees (in the remaining mutants) ; the maximum size attained by tapetal cells varies greatly; and the cell remains persist to varying degrees at anthesis.

It is tempting to propose in the face of this evidence that the genes for male sterility act fundamentally upon the tapetum, and that, since the pollen mother-cells and microspores are nurtured by the tapetum, the effects on microsporogenesis and development of the microspore are secondary. On the basis of this hypothesis, the degree of deviation of tapetal development might be expected to agree with the degree of deviation of pollen production. These two effects are somewhat correlated, but the agreement is not striking-for instance, tapetal development is least modified in $m s_{7}$, yet the breakdown in pollen production occurs earlier in this mutant than it does in $m s_{9}$ and $m s_{13}$, in which mutants tapetal development is more adversely affected.

The breakdown of the greatly enlarged tapetal cells is a feature of normal development; it is probably another manifestation of the transfer of nourishment from the tapetum to the pollen mother-cells and microspores in the same fashion that the embryo in many angiosperms develops at the expense of the endosperm. Hence a delayed breakdown of the tapetum might be construed as a more unfavorable influence on pollen production than one occurring at 
the normal time or even a premature breakdown. Earlier breakdown of pollen production does occur in mutants in which the degeneration of the tapetum is delayed, and the earliest breakdown is associated with the most persistent tapetum $\left(m s_{5}, m s_{10}\right)$. But, even if a perfect correlation could be drawn between the two processes, the effects both on pollen production and on development of the tapetum might still conceivably be wrought by an earlier and more fundamental action of the gene.

In eytoplasmically male-sterile sugar beets, Artschwager (1947) found that tapetal cells may lose their cell boundaries to form a periplasmodium, which invades the anther cavity at the expense of the microspores. This abnormal development was not found in the noncytoplasmic type; neither does it occur in any of the tomato mutants of the present study.

4. The genes conditioning male sterility act with remarkable precision. According to the foregoing account, the degree of precision varies, but, even in instances of variable effects, the precision is evident. Microsporogenesis in $m s_{7}$, for example, may be disrupted in any stage of meiosis, but it is limited to these stages; furthermore the full range of variation conditioned by the gene appears consistently in each flower bud. In respect to the development of normal pollen in certain microsporangia and interruptions at various stages in others, the mode of action of the $m s_{5}$ gene is less precise. When degeneration sets in during the microspore stage, the precision of gene effects is reflected in the uniformity of appearance of aborted microspores at anthesis. Thus, in $m s_{13}$, in which microspores break down at a relatively late stage, they exhibit remarkably little variation in size and afford a marked contrast with the extremely variable microspores produced by triploids, haploids, and asynaptic tomatoes.

5. The breakdown in tapetal development or in pollen production is somewhat correlated with size and shape of mature anthers and with size of corolla. The earliest degeneration in microsporogenesis and the most extreme deviation in tapetal development occur in $m s_{10}$, which also has the most deformed anthers; and the latest breakdown of development is associated with rather slight deformity of anthers in $m s_{9}$ and $m s_{13}$. No correlation exists, however, in the group of mutants that is intermediate with respect to anther form and time of degeneration. It is noteworthy also that the four mutants $\left(m s_{7}, m s_{8}\right.$, $m s_{10}, m s_{12}$ ) whose petal lengths are significantly reduced are also uniformly characterized by earlier breakdown of microsporogenesis than the other mutants. No correlation is found, however, within the group of significantly lesser petal length or within the group of mutants whose petal growth is not markedly affected.

In view of the less specific effect, and, in some examples, seeming absence of effect on size and form of anthers and corolla, it seems likely that these are not the primary effects of the gene, upon which the breakdown of pollen production depends. Evidence supporting this view is contributed by the fact that other genes in the tomato can exert such more drastic effects on the corolla as a reduction in the number or size of petals or a complete suppression of the corolla, with only a moderate, or even no, effect on pollen production (unpublished). These morphological effects of the male-sterility genes are certainly correlated with the effects on pollen production, and they both 
probably accrue from an earlier, more fundamental action of the gene, possibly on developmental hormones; but it appears very doubtful whether the breakdown of pollen production is a sequel to the general reduction in size of flower parts.

\section{OVULE FERTILITY}

Since the genes for male sterility exert such a pronounced effect on microsporogenesis and development of the male gametophyte, it is of interest to know what effect, if any, they have on the formation of ovules. From the start of this investigation it was known that each mutant was at least moderately fertile as a pistillate parent; otherwise, they would not have been recognized as male-sterile mutants. Yet a considerable abortion of ovules might easily have been overlooked in the preliminary observations.

TABLE 5

SUMMARY OF DATA ON OVULE FERTILITY

\begin{tabular}{|c|c|c|c|c|c|c|c|c|c|}
\hline \multirow[b]{2}{*}{ Mutant no. } & \multirow{2}{*}{$\begin{array}{c}\text { Total } \\
\text { ovules } \\
\text { examined }\end{array}$} & \multicolumn{3}{|c|}{ Per cent ovules of } & \multirow{2}{*}{$\begin{array}{c}\text { Total } \\
\text { fruits } \\
\text { examined }\end{array}$} & \multicolumn{4}{|c|}{ Mean number of seeds per fruit } \\
\hline & & $\begin{array}{c}\text { Normal } \\
\text { type }\end{array}$ & $\begin{array}{c}\text { Substi- } \\
\text { tution } \\
\text { type }\end{array}$ & $\underset{\text { type }}{\text { Collapsed }}$ & & 1945 & 1946 & 1947 & $\begin{array}{l}\text { Corrected } \\
\text { mean of } \\
\text { three yrs. }\end{array}$ \\
\hline Normal type.. & 107 & 97 & 0 & 3 & .. & & & $\ldots$. & $\ldots$ \\
\hline$m s_{5} \ldots \ldots \ldots \ldots$ & 103 & 93 & 5 & 2 & 21 & 35.1 & 34.6 & $\ldots$ & $34.9^{\prime}$ \\
\hline$m s_{6} .$. & 115 & 97 & 0 & 3 & 30 & 34.9 & 18.5 & 22.2 & 25.2 \\
\hline$m 87$. & 113 & 96 & 1 & 3 & 24 & 34.7 & 38.8 & $\ldots$ & 36.7 \\
\hline$m 88$. & 119 & 75 & 23 & 2 & 19 & 23.8 & $\ldots$ & 27.6 & 25.7 \\
\hline$m s 9 \ldots$ & 122 & 88 & 4 & 8 & 29 & 31.4 & $\cdots$ & 43.1 & 37.3 \\
\hline$m s_{10}$. & 123 & 89 & 5 & 6 & 19 & 28.6 & 23.2 & 36.5 & 29.4 \\
\hline$m s_{11}$. & 106 & 92 & 7 & 1 & 18 & 30.4 & 41.3 & $\ldots$ & 35.9 \\
\hline$m_{12} \ldots \ldots \ldots$ & 108 & 96 & 3 & 1 & 6 & $\ldots$ & $\ldots$ & 23.8 & 23.8 \\
\hline$m s_{13} \ldots \ldots$ & 112 & 87 & 1 & 12 & 6 & $\ldots$ & $\ldots$ & 34.7 & 34.7 \\
\hline
\end{tabular}

Ovule fertility was measured in two ways: by examining embryo sacs in sectioned ovules and by measuring the number of seeds in fruits formed after pollination with pollen from normal-type plants. Each technique suffers shortcomings, yet certain conclusions are justified by a joint analysis of the two approaches.

Ovaries of open flowers were prepared for examination, and the preparations were scanned for counts of functional and nonfunctional ovules according to techniques previously described (Rick, 1946). One hundred or more ovules were counted in small samples of 8 to 10 ovaries from each mutant. These counts are presented in table 5. Here "normal" type designates an ovule whose embryo sac is fully developed and has normal appearance, "substitution" and "collapsed" types representing nonfunctional ovules. As defined, a substitution ovule is one in which a megaspore mother-cell is never differentiated, or at least never proceeds through meiosis, but is replaced in later development by a mass of undifferentiated cells of the nucellus that substitute for the embryo sac. The collapsed type refers to ovules in which maturation proceeds at least to the megaspore stage, but the female gametophyte degenerates at this or some later stage of differentiation. A low level-3 to 5 per cent-of the collapsed type is characteristic of the normaltype plants, the substitution type appearing rarely in San Marzano. 
On the other hand, in all mutants except $m s_{6}$, the substitution type appears regularly. The normal level of sterile ovules is exceeded in all save $m s_{8}, m s_{7}$, and $m s_{12}$, although the excess is small and is statistically significant only in $m s_{8}$. According to this information a low level of ovule abortion might be characteristic of most of the mutants, but examination of much larger samples would be needed to reveal it.

It is noteworthy that, in keeping with the presence of substitution-type ovules in most mutants, the excess of sterile ovules in $m s_{8}$ is comprised entirely of this type. Ovules therefore degenerate at a comparatively earlier stage of development than the pollen mother-cells in this mutant. The preceding study (Rick, 1946) indicated that an unfavorable internal or external environment might induce development of the substitution-type ovule. A general suppression of growth of flower parts as observed in $m s_{8}$ might betray an adverse internal environment which might lead to this effect. Furthermore, 3 per cent or more of the substitution-type ovules are observed in all mutants whose petal lengths are significantly reduced.

The substitution and collapsed-type ovules in this survey are no doubt nonfunctional; but the ability of all ovules of normal appearance to function might be questioned. Nevertheless, most of them are able to develop into seeds according to the other measure of ovule fertility subsequently outlined.

Table 5 also presents the mean seed numbers per fruit obtained from matings of male-sterile and normal flowers in the backcrosses or allele test crosses previously described. Not only the variates, but also the means of the variates fluctuate markedly from mutant to mutant and from year to year. This high variability can be attributed partly to seasonal differences, to variation in the effectiveness of hand-pollination, and probably also to other factors. Because figures are not available for each mutant in each year, and because levels are much higher in 1946 and 1947 than in 1945, means for each mutant for the three-year period can be compared only if the individual means are corrected for yearly differences.

No comparable means for the normal-type plants are available. Seeds in fruits produced by self-pollination are not comparable because naturally self-pollinated flowers are not subject to a deficiency of pollen applied or pollinations made at ineffective times-factors that often reduce the seed set in hand-pollinations. Carefully emasculated and hand-pollinated flowers of the normal type might provide more comparable data; but even these are apt to provide unsatisfactory comparisons, especially in the later growth of the plant, when they often absciss or develop weakly in favor of undisturbed flowers.

Another possible disadvantage of these data is the fact that seed number per fruit is known to differ in different strains of San Marzano. The variation seen in the male-sterile mutants might be of the same nature, since they do not all necessarily represent the same strain. That the seed numbers may not always reflect differences in impairment of ovule fertility is suggested by the fact that, with one exception, they mostly vary independently of the counts of sterile ovules. The exceptional mutant, $m s_{8}$, has, in agreement with its significantly low level of functional ovules, a low, but not the lowest, mean seed number. 
Although these observations would not distinguish ovule sterilities of low grade-say 5 to 10 per cent-they do prove that an appreciably large ovule sterility exists only in the mutant $m s_{8}$.

\section{RATES OF NATURAL CROSS-POLLINATION}

The cultures grown at Davis in 1946 and 1947 gave an opportunity to compare the rates of natural cross-pollination of seven of the nine mutants and also to compare the rates in the two years. The plants in segregating families originally spaced 12 inches apart were thinned, after identification, to leave alternate fertile and sterile plants standing 4 to 5 feet apart in rows spaced 6 feet apart. Families of the different male-sterile mutants were scattered over an area in which fertile and male-sterile plants were represented in approximately equal numbers.

The proportion of flowers that set fruit in four plants of each mutant in each year was estimated in the following manner. Inflorescences were examined throughout the length of four branches, which were taken at random, and which originated at the crown of the plant. At the end of the growing season, when this observation is made, it is possible at Davis to distinguish accurately flowers that set fruit from those that failed to do so. The former are recognized by a greatly swollen pedicel to which the fruit may or may not be attached, and the latter, by a very slender pedicel. Two estimates of fruitfulness could thereby be obtained for each plant: the total number of fruits and the proportion of flowers that set fruit. Because parthenocarpy rarely occurs in San Marzano, fruit setting in this variety is a reliable indication of pollination and consequent seed formation.

The total number of fruits set on four representative branches is affected, of course, by the total growth of the plant as well as by the rate of natural cross-pollination. The proportion of flowers that set fruit might seem, on first consideration, to be a more reliable estimate of fruitfulness because plants differed in size and, consequently, in the total number of flowers produced. This argument is valid if any differences in total flower number indicate differences in the numbers of flowers that open during the midseason period when pollen vectors are most active (see line $B$, fig. 4 ). But growth is usually rather uniform during this period; differences in total flower production largely reflect differences in rate of growth at the end of the season, when the amount of available water, effects of virus disease, and other factors are more apt to vary from one plant to another and from one location in the field to another. Thus, the proportion of flowers that set fruit might be affected to a great extent by the end-season growth rate of the plant as well as by the relative activity of pollen vectors among the different mutants. It would be ideal to measure the desired proportion only for the period of vector activity, but no entirely objective way of segregating the data for this period could be found. At any rate, statistical analysis of each of the two measures gives very similar indications.

The mean values obtained for the proportion of flowers that set fruit are compared graphically in figure 2. Populations of the mutants $m s_{12}$ and $m s_{13}$ were not available in 1946, having been discovered too late for their backcross or $\mathrm{F}_{2}$ families to have been included in the plantings of that year. Data for 
normal-type plants are not included in figure 2 ; the liorizontal scale of this graph is too limited to include the 30 to 60 per cent level of fruitfulness observed in the normal-type plants.

The mean values for the proportion of flowers that set fruit and for total fruits per four branches were compared by means of analysis of variance. Before so treating the figures, it was necessary to apply the square-root transformation to the values for total fruits because their number is relatively low, and the arc-sine transformation to the data for proportion of flowers that set fruit (Snedecor, 1946). These analyses are summarized in table 6.

TABLE 6

ANALYSIS OF VARIANCE OF MEAN FRUIT NUMBERS AND PERCENTAGE OF FLOWERS SETTING FRUIT IN SEVEN MALE-STERILE MUTANTS, 1945 AND 1946

(Mean number of fruits per four branches; percentage of fruit by natural cross-pollination)

\begin{tabular}{|c|c|c|c|c|c|c|}
\hline & \multirow{2}{*}{$\begin{array}{l}\text { Degrees } \\
\text { of } \\
\text { freedom }\end{array}$} & \multicolumn{2}{|c|}{$\begin{array}{l}\text { Mean number of fruits } \\
\text { per four branches } \\
(\sqrt{\text { transformation })}\end{array}$} & \multicolumn{2}{|c|}{$\begin{array}{l}\text { Percentage of flowers } \\
\text { that set fruit } \\
\text { (angle transformation) }\end{array}$} & \multirow{2}{*}{$\begin{array}{c}F \\
\text { required } \\
\text { at } 1 \% \\
\text { level }\end{array}$} \\
\hline & & $\begin{array}{l}\text { Mean } \\
\text { square }\end{array}$ & $F$ & $\begin{array}{c}\text { Mean } \\
\text { square }\end{array}$ & $F$ & \\
\hline Mutants.. & 6 & 1.491 & 12.12 & 26.38 & 21.45 & 8.47 \\
\hline Years..................... & 1 & 0.045 & 0.37 & 0.59 & 0.48 & 5,859 \\
\hline Error & 6 & 0.123 & - & 1.23 & - & - \\
\hline
\end{tabular}

There was close agreement in the levels of cross-pollination for the two years (fig. 2, and $F$ values for years in table 6 ). The mutants, on the other hand, contribute a very great share of the observed variation, the $F$ values being highly significant.

The natural fruit set of $m s_{\text {, }}$ is significantly much higher than that of any other mutant. This result might have been anticipated because fruits can be set on this mutant by self-pollination as well as by natural cross-pollination. The relative share contributed by these two sources cannot be estimated by any available data, but might be ascertained by observing the number of fertile and male-sterile offspring in the progeny derived from open-pollination of plants of this mutant surrounded by homozygous normal plants.

The lowest values were observed in the mutant $m s_{10}$. The percentage of flowers that set fruit in this mutant was significantly lower than the next lowest mutant at the 5 per cent level and lower than the remaining five mutants at the 1 per cent level. The number of fruits set by this mutant is significantly lower than that of five other mutants at the 5 per cent level and of three others at the 1 per cent level.

In the group having intermediate rates-that is, $m s_{6}, m s_{8}, m s_{9}$, and $m s_{11}$ differences significant at the 5 per cent level exist only between the extremes. These statisties cannot therefore decide with great certainty whether this intermediate group represents one or more infinite populations in respect to levels of natural cross-pollination; but the following comparisons of these data with measurements of anthers suggest that some of these differences may be inherent. 
The very low level of $m s_{10}$ cannot be attributed to any defect of the pistil, because transfer of pollen from the normal type to stigmas of this mutant is followed by normal fruit formation with a full complement of seed, and microscopic examination of ovaries does not reveal any appreciable abortion

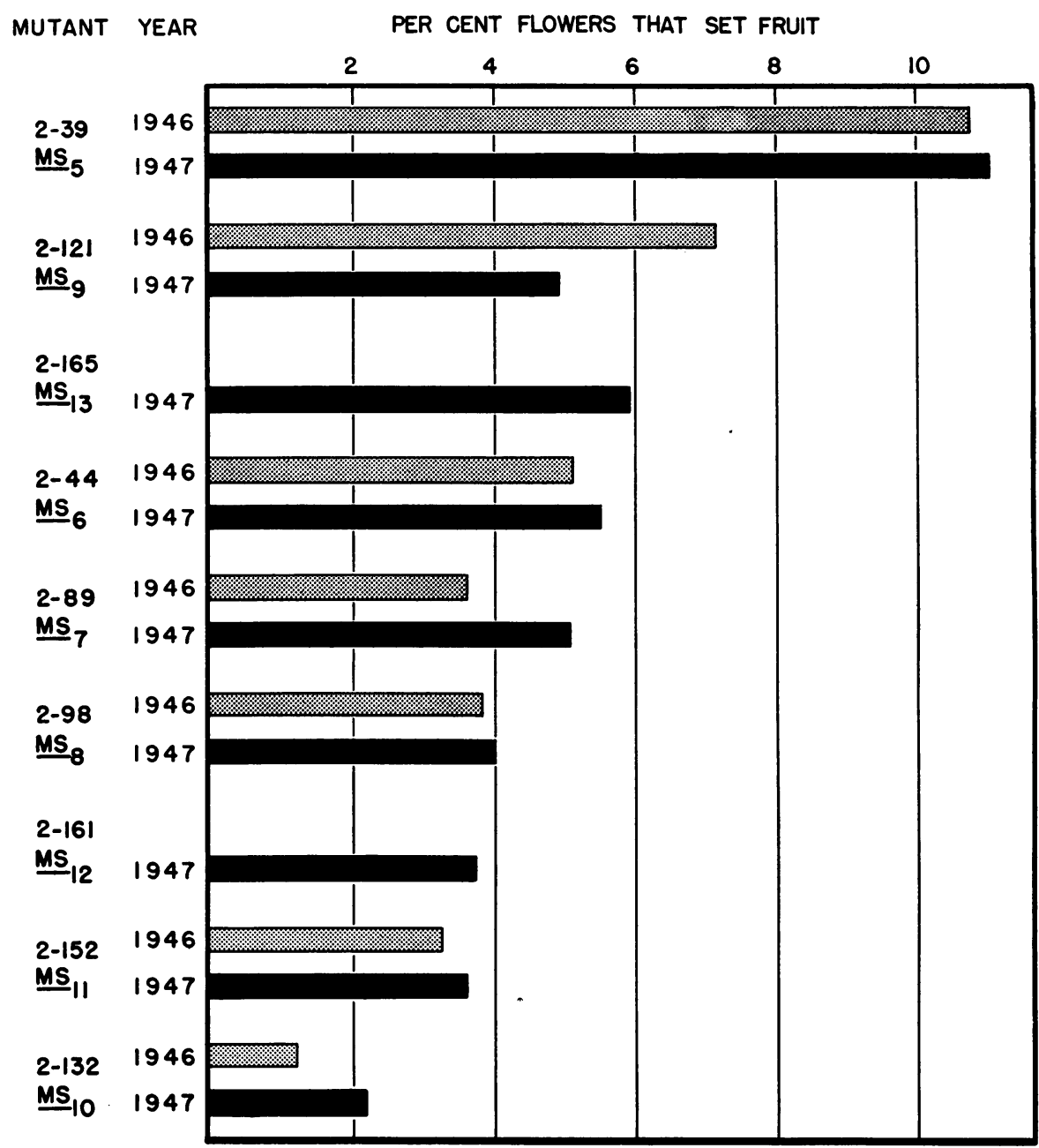

Fig. 2. Rates of natural cross-pollination of the nine mutants during 1946 and 1947.

of embryo sacs (table 5) ; in fact, none of the ovule sterilities observed in these mutants are high enough to affect fruit setting. It is interesting that the greatest depression of anthers occurs in this mutant, aside from the most extremely reduced flowers of $m s_{5}$. Measurements (product of length and diameter) of anthers were compared with rates of cross-pollination to see if this relation might prevail in other mutants. Sufficient data exist to permit adding $m s_{12}$ and $m s_{13}$ to this group. Since $m s_{5}$ is subject to self-pollination under field conditions, it is not included in these comparisons. Means of five 
flowers. of each mutant were compared with the proportion of flowers that set fruit for the eight mutants, $m s_{6}$ to $m s_{13}$. The array strongly suggests a curvilinear relation between these two measures. If the proportion of flowers that set fruit is plotted against the log of the product of the anther-tube measurements (fig. 3), the suggestion of a curved relation is diminished, and the correlation coefficient is increased to 0.75 , which, according to Fisher's (1944) $t$ test of the correlation coefficient, is significant at the 5 , but not at the 2, per cent level. The coefficient is not highly significant, and the low

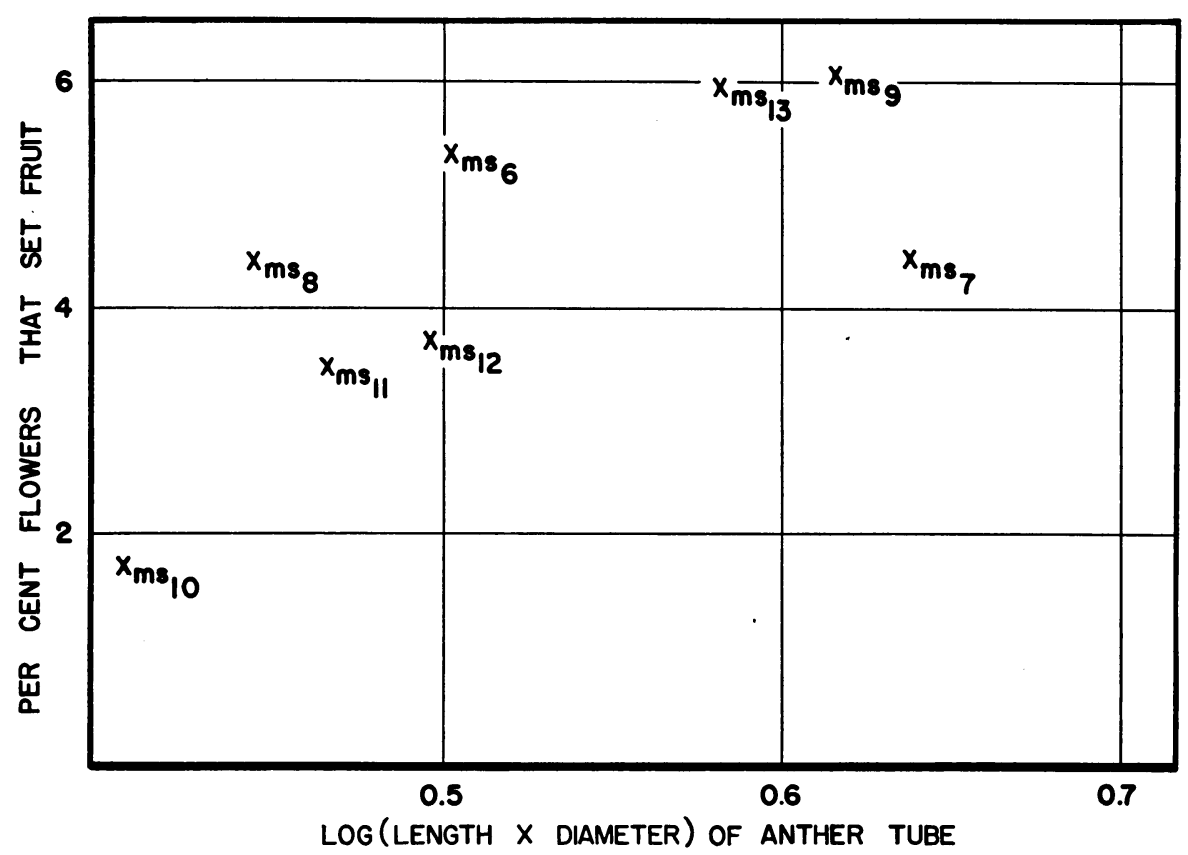

Fig. 3. Scatter diagram of eight male-sterile mutants (omitting $m s_{i}$ ), showing the relations between the rate of natural cross-pollination and the size of anther tube.

values of both measurements for $m s_{10}$ doubtless contribute greatly to the high value of the coefficient; hence the limited data available strongly suggest, but do not prove beyond doubt, that the rate of natural cross-pollination decreases as anthers decrease from normal size. A study of more mutants would be needed to prove the existence of this correlation and, if it were demonstrated, to establish the nature of the relation between the two variables.

Comparisons between natural cross-pollination and such other variables of the mutant flowers as size of corolla and color of anthers do not reveal any such pronounced relation.

While the ovule fertilities give no clues, the habits of the pollen vectors provide a likely explanation of this correlation. The careful choice that honeybees make in selecting flowers to visit is an everyday observation. Similarly, the species of native solitary bees that are responsible for the transfer of tomato pollen at Davis have been observed to hover close to the tomato inflorescences and to visit only certain flowers, as if they preferred flowers of 
a characteristic form or location. They might conceivably prefer tomato flowers with anthers that more nearly approximate the normal type and tend to pass by those with more deformed anthers. Accordingly, the rate of natural cross-pollination might be expected to decrease as the form and size of anthers depart from the normal type.

This hint as to the habits of the insect pollen vectors might be significant in respect to the evolutionary role of differences in flower form within species. Cross-pollination serves to maintain a high level of variability and consequent versatility of the species and the capacity to succeed in changing environments. Examples of the many devices in higher plants that ensure cross-pollination are familiar to every biologist. The present example suggests that, even in a species that is regarded as highly self-pollinating, departures from normal flower form may discourage visits of insect vectors and consequently have a lower selective advantage in a changing environment.

As in other aspects of the present investigation, the mutant $m s_{5}$ is exceptional. Even if its rate of natural cross-pollination could be estimated, comparisons of this rate with those of the other mutants would scarcely be valid because $m s_{5}$ is subject to exceedingly great variability in the reduction of its anthers. The range of variation extends from anthers that closely approach the normal type to others that are more depressed and deformed than those of any other mutant (plate 1). In contrast, the anthers of each of the other mutants show a surprising degree of uniformity in size and form.

A further hint as to vector habits is contributed by additional considerations of this exceptional mutant. In 1946 plants of this type were grown in complete isolation, being located at least 1,000 yards from any normal, fruiting tomatoes, with the hope that the seasonal setting behavior might give a clue as to the environmental effect on the expression of this gene. Preliminary observations had not, however, given any indication that the degree of anther development of $m s_{5}$ varies according to season; as a matter of fact, the full range of variation is seen on a single plant at the same season, whether summer or fall in the field, or winter or spring in the greenhouse. The seasonal fruit setting of $m s_{5}$ in isolation is illustrated by line $C$ in figure 4. This line is compared in the same graph with the seasonal setting of the same mutant growing among normal-type plants (line $A$ ) and the mean seasonal setting of other male-sterile mutants growing among normal-type plants (line $B$ ). In other words, line $B$ represents the seasonal variation in the amount of natural cross-pollination obtained in male-sterile mutants that do not produce any viable pollen; line $C$ represents the seasonal variation in the amount of fruit setting that is conditioned by the pollen production of $m s_{5}$ alone; while line $A$ represents the seasonal variation in $m s_{5}$ when fruits can develop both from cross-pollination with surrounding plants and from self-pollination. The shape of the $B$ curve is quite typical of those normally obtained for seasonal fruit setting on male-sterile plants at Davis. The curve rapidly climbs to a maximum in late July, falling afterward, but at a less rapid rate to a zero value usually reached in mid-September. The $A$ and $C$ curves for $m s_{5}$ show generally the same shape; in fact the coincidence of maximas for all three curves is striking. The $A$ and $C$ curves differ from the $B$ curve, however, in maintaining a continued although low level of fruit setting from 
mid-September until the end of the season. This can be accepted as the only reliable estimate of natural self-pollination of $m s_{5}$.

Since the anthers of $m s_{-}$vary greatly in form and ability to produce functional pollen, it might be presumed that the seasonal pattern of fruiting of this mutant (curve $C$ ) could be explained by a variable proportion of pollenproducing, self-pollinating flowers corresponding to the levels of fruit set at various parts of the season. But no such variation has been observed : instead, the same general proportion of flowers with different degrees of anther deformity appears at all times of the year. The great similarity in shape of the three curves suggests a more likely explanation. Curve $B$ must represent the

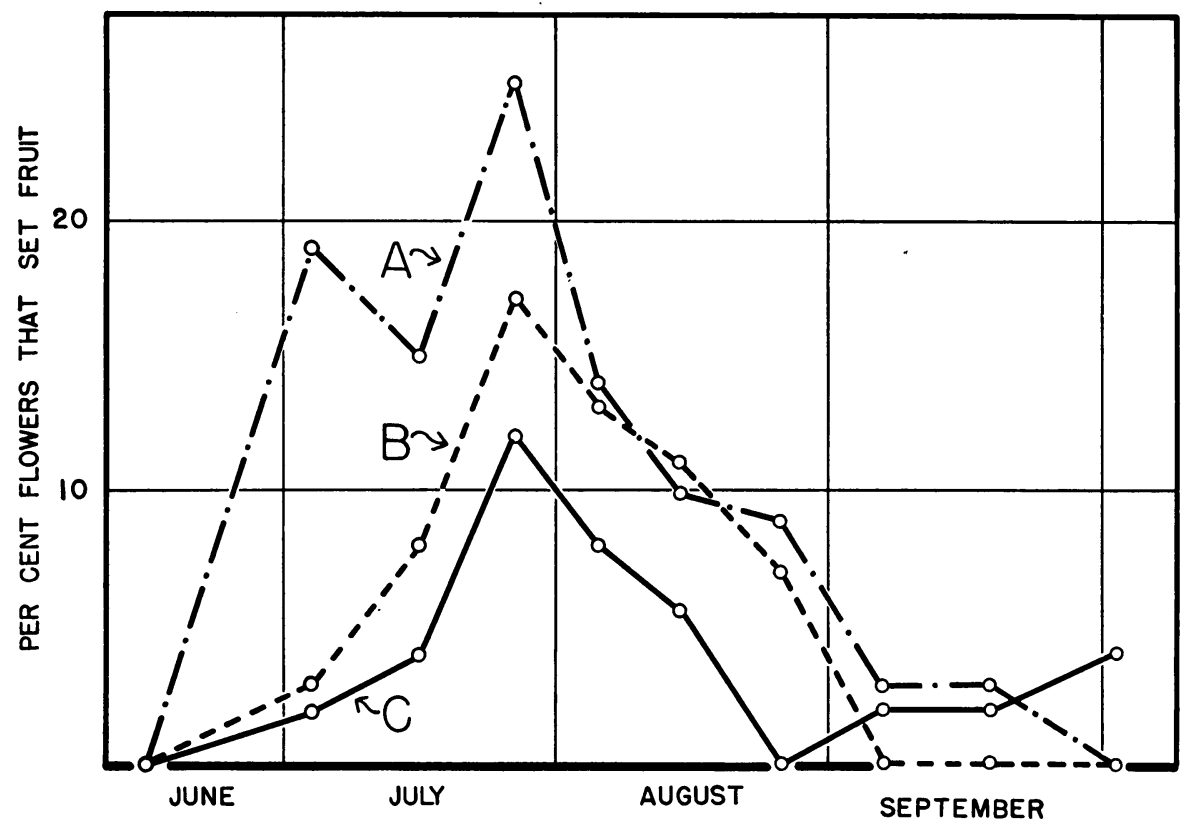

Fig. 4. Seasonal variation in the rate of natural eross-pollination: $A, m s_{5}$ surrounded by fertile plants; $B$, mean values for plants of other male-sterile mutants surrounded by fertile plants; $C, m s_{5}$ isolated from fertile plants.

seasonal pattern of activity of the tomato pollen vectors because the mutants represented in this curve will set fruit only if functional pollen is transferred to them. Also, the increased levels of curve $A$ in respect to curve $C$ must be explained in terms of insect vector activity. It therefore seems more in keeping with the evidence that insect vectors are mainly responsible for the pollination and the resulting fruit setting of the $\mathrm{ms}_{5}$ mutant, even if it is isolated by distance from fertile tomatoes.

Another fact that lends support to this interpretation is the observation that a considerable number of fruits was set on plants of $m s_{9}$ growing close to the plants of $m s_{5}$ in the isolated plot. The mutant $m s_{9}$ is known to be completely male-sterile because it has never set fruits containing seeds when isolated from all sources of viable tomato pollen. The fruits set on $m s_{9}$ in this planting must therefore have resulted from the transfer by insect vectors of pollen, limited though it must have been, from $m s_{5}$. 
If these observations have been interpreted correctly, they reveal a keen ability of the native solitary bees to select the pollen-bearing flowers of the $m s_{5}$ mutant. If the insect is guided by the shape and size of the anthers, as the earlier analysis suggests, the results might not seem so extraordinary because, in tending to visit the flowers that more nearly resemble the normal type, the insect would have a greater chance of finding one that would yield normal pollen, and would thereby increase the fruit setting of this mutant.

The foregoing considerations of the fruit setting of the male-sterile mutants reveal surprising suggestions concerning the habits of the pollen vectors. Also unexpected was the information regarding the amount of pollen transferred on a single visit and the distance over which a vector might forage on a single flight gained in an analysis of the pollinating relations of the $d l$ mutant (Rick, 1947). Additional information-for instance, the relative activity of vectors in different localities - can be gained by appropriate experiments with these mutants.

\section{FREQUENCY OF MALE-STERILE MUTATIONS}

The present survey adds nine $m s$ genes to four that had already been discovered in Lycopersicon esculentum. In 16 male-sterile plants collected in tomato fields, therefore, 13 different genes are involved. The data are still too meager to provide an estimate of the total number of genes for male sterility in this species, but the number is probably very much higher than 13 .

In addition to these mutants, another one, probably representing a new gene, has been discovered recently in the variety Earliana. Preliminary genetic studies indicate that this male sterility is probably likewise conditioned by a single recessive gene.

The abundance of genes for male sterility in tomatoes is by no means unique in flowering plants. Such genes have been reported in at least 19 different species in widely separated taxonomic groups. Furthermore, in species which have been subjected to more intensive genetic study, they have been recovered with comparable frequency - for instance, at least 23 genes for male sterility are known in maize (Beadle, 1932 ; Emerson, Beadle, and Fraser, 1935).

On first thought the repeated recovery of $m s_{5}$ might be attributed to its ability to produce a small quantity of functional pollen. While this exceptional ability increases the reproductive capacity of this mutant, it does so only to a slight extent. Though the amount of seed produced by self-pollination of $m s_{\text {; }}$ has never been measured, it cannot amount to more than 5 per cent of that produced by fertile plants. Now, if it is assumed that $M s_{5} m s_{\tilde{5}}$ plants reproduce at the same rate as the other fertile plants in the field, the proportion of such plants should be halved in each generation. One quarter of their offspring will be $m s_{i} m s_{z}$, which will breed true, but reproduce at 5 per cent or less of the rate of $M s_{i} m s_{\overline{5}}$ and other fertile plants. This additional yield of homozygotes accumulated from self-pollination of homozygotes amounts to only about 10 per cent of the number that are yielded by the heterozygotes. Furthermore, in collecting seed, seedsmen may tend to avoid plants that are as unfruitful as $m s_{i} m s_{i}$.

It seems more likely, therefore, that this gene was recovered repeatedly because a large proportion of the heterozygote was included, as a result of chance 
or higher mutation rate, in the plantings that were the predecessors of the ones in which unfruitful plants were sought.

Absence of Cytoplasmically Male-sterile Mutants. No cytoplasmically male-sterile mutants were discovered in the samples of unfruitful tomato plants. Since the tomato is very highly self-pollinated, all factors that cause sterility, whether of pollen or ovule or both, would enjoy equal opportunity of discovery.

Cytoplasmic male sterility is generally much less common in cultivated plants than genic male sterility, but examples are known in maize (Rhoades, 1933), onions (Jones and Clarke, 1943), and sugar beets (Owen, 1945). If the cytoplasm regulates expression of the known male-sterile mutants in tomatoes, it is favorable toward all, and, in this sense, all investigated lines might be said to have the appropriate cytoplasmic factor.

Male sterility determined exclusively by the cytoplasm (as in maize) could be reproduced at a rate that would depend on the proportion of natural crosspollination. In tomatoes, because the rate of natural cross-pollination is very low, the reproductive rate of this type would be correspondingly low. If the determination is based on an interaction of a cytoplasmic factor and one or more genes (as in onions and sugar beets), reproduction at a much higher rate could occur by self-pollination of the fertile heterozygotes having the sterile-type cytoplasm. But any masking of the male-sterile genes by the nonsterile cytoplasm would serve to prevent recovery of the male-sterile phenotypes; the genes of such plants would never attain phenotypic expression except for the small extent to which they might be transferred by natural cross-pollination to plants having the appropriate sterile cytoplasm. In highly self-pollinated crops, therefore, male sterility determined by cytoplasmic factors would tend to disappear more quickly than that determined solely by genes; and it is therefore not surprising that no cytoplasmic factors were found in this crop.

Absence of Female-sterile Mutants. The absence of female sterility in tomatoes is matched by a similar situation in other genetically analyzed cultivated plants. The term female sterility here refers to an effect on ovule production analagous to that on pollen production in male-sterile mutants; in other words, it is a complete breakdown in megasporogenesis or development of the female gametophyte without adverse effect on the development of functional pollen. Emerson, Beadle, and Fraser (1935) list over 300 genes, including 23 for male sterility, known in maize, but only one (silkless) is female-sterile. Several other mutants, such as barren stalk, are effectively female-sterile, but in them, the entire pistillate inflorescence is absent, and they are therefore not strictly comparable to the male-sterile mutants, in which the sex organ is present but fails to produce functional gametes.

Although female-sterile mutants have not been found in tomatoes, others are known that are both female and male-sterile (Rick, 1945a). Because the latter have never appeared in segregating families, it has been impossible to obtain any information concerning their heredity. It seems quite likely, however, as with the mutants which can be bred, that they are genetically determined.

It is known that mature pollen and the developmental stages leading to the 
production of pollen are more sensitive to unfavorable environments than those of embryo sacs. Wheat, for instance, can be emasculated by chilling the emerging heads (Suneson, 1937); the pollen of Sorghum can be destroyed without injury to other floral parts by heat treatments (Stephens and Quinby, 1933 ) ; and heat treatments applied to maize as early as the seedling stage will effectively induce male sterility (Jones, 1947). Now, if the effects of the genes on gamete formation and also those on the size of floral parts accrue as pleiotropic effects of some earlier and more fundamental action, the absence of true female sterility might be understood. In the light of these physiological experiments, the less severe action might lead to male sterility only, and the more drastic action to total sterility, an effect solely on the female gametes being impossible in this scheme.

\section{USE OF THE MALE-STERILE MUTANTS FOR CONTROLLED CROSS-POLLINATION}

Any of the mutants described in this study could be used advantageously as pistillate parents in controlled cross-pollination. With one exception all are completely pollen-sterile; again, with one exception, they show no great degree of ovule sterility. Some of them, however, present certain advantages that are not shared by others.

In producing large numbers of male-sterile segregates of any mutant, ease of identification would be an important consideration. To be sure, all the mutants can be identified macroscopically by prodding the anthers with a blunt instrument, like the tips of a forceps, in order to detect whether large masses of normal pollen are formed. But such a technique is much more tedious than identification of the segregates by means of discernible differences in color, size, or shape of anthers.

Exsertion of the stigma is another important practical consideration, for it permits much easier hand-pollination than nonexserted stigmas which are sunken below the apex of the anther tube. In respect to these two factorsease of macroscopic identification and degree of stigma exsertion-mutants $m s_{5}, m s_{8}, m s_{10}$, and $m s_{12}$ would be most desirable; $m s_{9}$ and $m s_{13}$ would be least useful, while $m s_{6}, m s_{7}$, and $m s_{11}$ would occupy an intermediate level of desirability for the production of hybrid seed.

A third factor that deserves consideration is the rate of natural crosspollination to which the mutant is subject. Though the amount of seed that can be produced in this way is limited in many localities, it might provide a sufficiently welcome addition to the hybrid seed produced by hand-pollination to merit the interplanting of the male-sterile mutant and the fertile pollen parent. In respect to this factor, the lesser the degree of anther deformity, apparently the greater the rate of cross-pollination and consequently the more desirable the mutant. This consideration might disqualify $m s_{10}$ because of its much lower rate. It might be well, therefore, to select mutants such as $m s_{6}$, and $m s_{7}$, which satisfy the first two qualifications, and, at the same time, are subject to a relatively high rate of insect pollination.

At this point $m s_{5}$ again deserves special consideration. Because it can produce functional pollen, it offers the unique advantage of being self-pollinating and therefore reproducible in 100 per cent of the progenies derived from self- 
pollination. In contrast, the maximum yield of male-sterile individuals of all other mutants is the 50 per cent obtainable from backerosses. From the standpoint of large-scale production of $F_{1}$ hybrid seed, the advantage of this mutant does not lie so much in the higher yield of sterile plants as it does in the elimination of any need for growing segregating populations to the flowering stage for identification of the sterile segregates before they are planted in the field. Exclusively male-sterile progenies of $m s_{\text {; }}$ can be produced by controlled selfpollinations or by open pollinations of the sterile plants grown under complete isolation, or by a combination of both methods. Extraction of pollen is tedious and might seriously limit the feasibility of self-pollination by hand. On the other hand, the mechanical pollen collector invented by Cottrell-Dormer (1945) might possibly be used to advantage here.

By the very token of pollen production, which permits the generation of 100 per cent male-sterile populations, the use of $m s_{\overline{5}}$ as a pistillate parent in the production of hybrid seed would be at a disadvantage because such hybrid seed would be contaminated by a low proportion of seed resulting from selfpollination. Though very intensive cross-pollination might serve to reduce this self-contamination to a low level, even a very small proportion of such contaminants would be objectionable because they would necessarily be malesterile and unfruitful. This difficulty might be circumvented in several ways. First, the proportion of contamination might be reduced or completely eliminated by pollinating only the flowers that have the greatest reduction of anthers and by pulling off the remaining ones that approach the normal type. As previously described, the degree of abnormality of anthers in this mutant is inversely related to the amount of functional pollen produced. Second, the 'undesirable sterile contaminants could be identified by the use of a recessive seedling character, as previously suggested for a similar purpose by Currence (1944). If, for example, the male-sterile stock were homozygous for $a_{1}$, the gene determining the absence of anthocyanin pigment, and the desired pollen parent were true-breeding for the dominant allele, the $\mathrm{F}_{1}$ hybrid seedlings could be distinguished by the purplish color of their hypocotyls from the selfcontaminants, which would have green hypocotyls.

Another development that greatly affects the use of genetic male sterility in producing $\mathrm{F}_{1}$ tomato hybrids is the recent description of a mechanical pollen collector by Cottrell-Dormer (1945). Heretofore considerable time has been required in the tedious operation of forcing pollen from the anthers of the desired pollen parent. This simple device, consisting of an electric vibrator, efficiently shakes the pollen from the anther tubes into replaceable glass cups. One can collect sufficient pollen with it to last for an entire day of pollinating. If this device were used to collect pollen from the staminate parent, and if male-sterile lines were used to circumvent emasculation of the pistillate parent, the cost of hybrid tomato seed production should be greatly reduced.

\section{ACKNOWLEDGMENTS}

It is a pleasure to acknowledge the competent help of the following assistants : Toni Fatjo and Martha O. Rick made many of the pollinations; Donald C. McGuire and Robert K. Soost assisted in scoring test families; most of the slides were prepared by Jeanette Robinson. 


\section{LITERATURE CITED}

Artschwager, E.

1947. Pollen degeneration in male-sterile sugar beets, with special reference to the BEAdLE, G. W. tapetal plasmodium. Jour. Agr. Res. 75:191-97.

1932. Genes in maize for pollen sterility. Geneties 17:413-31.

CoTTRELl-DORM ER, W.

1945. An electric pollinator for tomatoes. Queensl. Jour. Agr. Sei. 2:157-69.

Crane, M. B.

1915. Heredity of types of inflorescence and fruits in tomato. Jour. Genetics 5:1-11.

Currence, T. M.

1944. A combination of semi-sterility with two simply inherited characters that can be used to reduce the cost of hybrid tomato seed. Amer. Soc. Hort. Sei. Proc. 44:403-6.

Emerson, R. A., G. W. Beadle, and A. C. Fraser.

1935. A summary of linkage studies in maize. New York Agr. Exp. Sta. (Cornell) Mem. $180: 1-83$.

Fisher, R. A.

1946. Statistical methods for research workers. 10 th ed. $x v+354$ p. Oliver and Boyd, JoNes, D. F. Edinburgh.

1947. Effect of temperature on the growth and sterility of maize. Science 105:390-91.

Jones, H. A., and A. E. Clarke.

1943. Inheritance of male sterility in the onion and the production of hybrid seed. Amer. Soc. Hort. Sci. Proc. 43:189-94.

Lesley, J. W., and MargareT M. Lesley.

1939. Unfruitfulness in the tomato caused by male sterility. Jour. Agr. Res. 58:621-30.

LEWIS, D.

1942. The evolution of sex in flowering plants. Biol. Rev. 17:46-67.

OWEN, F. V.

1945. Cytoplasmically inherited male-sterility in sugar beets. Jour. Agr. Res. 71:423-40. RHOADES, M. M.

1933. The cytoplasmic inheritance of male sterility in Zea Mays. Jour. Genetics 27:71-93.

RICK, C. M.

1944. A new male-sterile mutant in the tomato. Science 99:543.

1945a. A survey of eytogenetic causes of unfruitfulness in the tomato. Genetics 30:347-62.

$1945 \mathrm{~b}$. Field identification of genetically male-sterile tomato plants for use in producing $\mathrm{F}_{1}$ hybrid seed. Amer. Soc. Hort. Sci. Proc. 46:277-83.

1946. The development of sterile ovules in Lycopersicon esculentum Mill. Amer. Jour. Bot. 33:250-56.

1947. Partial suppression of hair development indirectly affecting fruitfulness and the Sмiтн, O. proportion of eross-pollination in a tomato mutant. Amer. Nat. 81:185-202.

1935. Pollination and life-history studies of the tomato (Lycopersicon esculentum Mill.)

SNEDECOR, G. W. New York Agr. Exp. Sta. (Cornell) Mem. 184:1-16.

1946. Statistical methods. 4th ed. xvi +485 p. Iowa State College Press, Ames, Iowa.

Stephens, J. C., and J. R. Quinby.

1933. Bulk emasculation of sorghum flowers. Amer. Soc. Agron. Jour. 25:233-34.

Suneson, C. A.

1937. Emasculation of wheat by chilling. Amer. Soc. Agron. Jour. 29:247-49.

ZiELINSKI, QUENTIN.

1945. Fasciation in horticultural plants with special reference to the tomato. Amer. Soc. Hort. Sci. Proc. $46: 263-68$. 

The journal Hilgardia is published at irregular intervals, in volumes of about 600 pages. The number of issues per volume varies.

Subscriptions are not sold. The periodical is sent as published only to libraries, or to institutions in foreign countries having publications to offer in exchange.

You may obtain a single copy of any issue free, as long as the supply lasts; please request by volume and issue number from:

\section{Publications Office \\ College of Agriculture \\ Berkeley 4, California}

The limit to nonresidents of California is 10 separate issues on a single order. A list of the issues still available will be sent on request. 


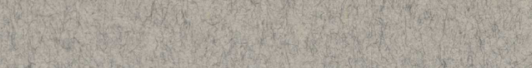

$x^{2}$

W. $4 x^{2}$ (1) (1) Thing

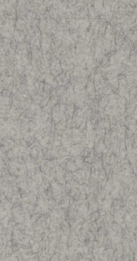

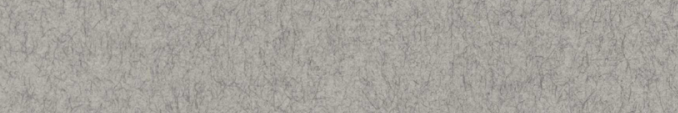

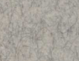

$x_{3},-1$

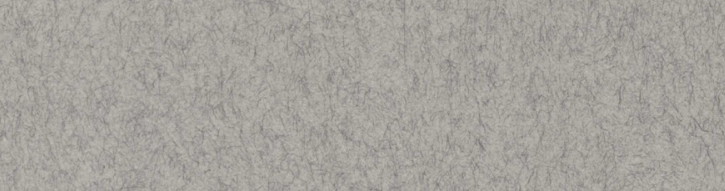

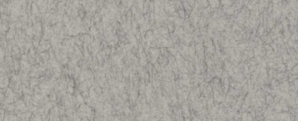

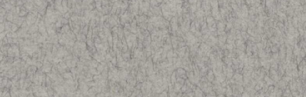

19.2.

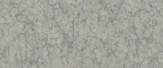

